This item was submitted to Loughborough's Research Repository by the author.

Items in Figshare are protected by copyright, with all rights reserved, unless otherwise indicated.

\title{
Roller bearing dynamics under transient thermal-mixed non-Newtonian elastohydrodynamic regime of lubrication
}

PLEASE CITE THE PUBLISHED VERSION

http://dx.doi.org/10.1177/1464419315569621

\section{PUBLISHER}

SAGE Publications / @ IMechE

VERSION

AM (Accepted Manuscript)

\section{PUBLISHER STATEMENT}

This work is made available according to the conditions of the Creative Commons Attribution-NonCommercialNoDerivatives 4.0 International (CC BY-NC-ND 4.0) licence. Full details of this licence are available at: https://creativecommons.org/licenses/by-nc-nd/4.0/

\section{LICENCE}

CC BY-NC-ND 4.0

\section{REPOSITORY RECORD}

Mohammadpour, Mahdi, P.M. Johns-Rahnejat, and Homer Rahnejat. 2019. "Roller Bearing Dynamics Under Transient Thermal-mixed Non-newtonian Elastohydrodynamic Regime of Lubrication". figshare. https://hdl.handle.net/2134/16936. 


\title{
Roller bearing dynamics under transient thermal-mixed non-Newtonian elastohydrodynamic regime of lubrication
}

\author{
M. Mohammadpour, P.M. Johns-Rahnejat and H. Rahnejat* \\ Wolfson School of Mechanical and Manufacturing Engineering, Loughborough University, \\ Loughborough, UK \\ *Corresponding author: H.Rahnejat@lboro.ac.uk
}

\begin{abstract}
:
The paper describes a combined tribodynamics analysis (dynamics and contact tribology) of cylindrical roller bearings of a heavy duty truck transmission under high applied loads. The dynamic analysis provides the transient variations in contact load. It also determines the vibration spectrum of the bearing as well as that of contact dynamics. It is shown that with sufficient preloading and/or interference fitting a widely spread loaded region results, which reduces bearing-induced vibration. The transient tribological analysis, including thermal analysis with a novel and realistic lubricant inlet boundary condition demonstrates that nonNewtonian mixed elastohydrodynamic regime of lubrication is prevalent, but with reduced friction compared with unrealistic dry Coulombic friction, which is often assumed in literature.
\end{abstract}

\section{Keywords:}

Roller bearings, Dynamic analysis, Bearing vibration, Thermal mixed-elastohydrodynamics, non-Newtonian friction

\section{Nomenclature:}

A Apparent contact area

$A_{a} \quad$ Asperity contact area

C Radial clearance

c Heat capacity of the lubricant

$c_{r o} \quad$ Specific heat capacity of roller material

$c_{r a} \quad$ Specific heat capacity of race material

$E_{r} \quad$ Reduced Young's modulus of elasticity, $E_{r}=\frac{\pi}{\left[1-v_{b}^{2} / E_{r o}\right]+\left[1-v_{r}^{2} / E_{r a}\right]}$

$E_{r o}, E_{r a}$ Young's modulus of elasticity for roller and race materials

$F_{x} \quad$ Excitation force in the transverse $x$-direction 
$F_{y} \quad$ Excitation force in the transverse $y$-direction

$f_{b} \quad$ Boundary friction

$f_{c} \quad$ Cage frequency

$f_{n} \quad$ Bearing base natural frequency

$f_{r} \quad$ Roller-passage frequency

$g \quad$ Gravitational acceleration

$h_{i} \quad$ Lubricant film thickness of roller $i$ to race contact

$h \quad$ Lubricant film thickness in the EHL model

$h_{c 0} \quad$ Central film thickness

$k_{n} \quad$ Stiffness of inner ring-roller-outer ring contact

$k_{f} \quad$ Lubricant conductivity

$k_{\text {ro }} \quad$ Thermal conductivity of roller material

$k_{r a} \quad$ Thermal conductivity of race material

$k \quad$ Ratio of surface speeds of the contiguous solids

$M \quad$ Rotor mass

$m \quad$ Number of rollers

$m_{i} \quad$ Inlet distance to the conjunction

$m_{e} \quad$ Outlet distance from the conjunction

L Roller length

$l_{d} \quad$ Length of the dub-off region

$P_{m} \quad$ Average contact pressure

$p \quad$ Hydrodynamic pressure

$R_{d} \quad$ Dub-off radius

$R_{z x} \quad$ Equivalent radius of contact of an ellipsoidal solid against a semi-infinite elastic halfspace

$R_{\text {ro }} \quad$ Roller radius

$R_{r a} \quad$ Radius of race 


\section{$T \quad$ Temperature}

$T_{0} \quad$ Inlet temperature of the contact

$t \quad$ Time

$U \quad$ Speed of entraining motion

$U_{\text {ro }} \quad$ Roller surface speed

$U_{r a} \quad$ Race surface speed

$W_{a} \quad$ Asperity contact load

$W_{i} \quad$ Applied load on roller $i$

$w_{i} \quad$ Squeeze velocity for roller $i$ to race contact

$X, Y \quad$ Spatial Co-ordinates in the contact conjunction

$x, y \quad$ DOFs of bearing centre

Z Normal direction to the contact

\section{Greek symbols}

$\alpha \quad$ Pressure-viscosity coefficient of the lubricant

$\beta \quad$ Average asperity summit radius

$\bar{\beta} \quad$ Temperature viscosity coefficient

$\delta_{i} \quad$ Contact deflection of roller $i$

$\varepsilon_{p} \quad$ Computational error for pressure convergence

$\varepsilon_{T} \quad$ Computational error for thermal balance

$\varepsilon_{W} \quad$ Computational error for instantaneous quasi-static equilibrium

$\xi \quad$ Asperity distribution per unit contact area

$\eta_{0} \quad$ Atmospheric lubricant dynamic viscosity

$\eta \quad$ Lubricant dynamic viscosity

$\theta_{i} \quad$ Angular position of roller $i$

$\lambda \quad$ Stribeck's oil film parameter

$v_{r o}, v_{r a}$ Poisson's ratio for roller and race material 
$\bar{\rho} \quad$ Radial interference fit

$\rho \quad$ Lubricant density

$\rho_{0} \quad$ Atmospheric lubricant density

$\rho_{\text {ro }} \quad$ Density of roller material

$\rho_{r a} \quad$ Density of race material

$\sigma \quad$ Root mean square composite surface roughness

$\tau_{L} \quad$ Limiting shear stress

$\tau_{v} \quad$ Viscous shear stress

$\tau_{0} \quad$ Limiting shear stress at atmospheric pressure

$\phi_{i} \quad$ Angle of fluid inlet point

$\phi_{e} \quad$ Angle of fluid outlet point

$\chi \quad$ Slope of limiting shear stress with pressure

\section{Introduction:}

Rolling element bearings often determine the performance limit of the machine that they are a part. Their response is affected by a host of interacting parameters under a wide range of operating conditions, including variable contact loads, speeds and temperatures. Bearing performance is often ascertained with respect to key performance measures which include friction and wear [1], fatigue [2,3], thermal stability [4] and generated vibration and noise [57]. The selection and useful life of a bearing are critically dependent on all these measures. Therefore, any predictions should be based on a combination of dynamic analysis and the prevailing tribological contact conditions.

Ball and rolling elements in a bearing undergo complex motions, such as rolling and sliding motion with respect to the inner and outer raceway grooves, as well as mutual convergence or separation of bearing rings under oscillating conditions [8]. These motions are caused by variations in the applied load transmitted to the bearing as well as contact conditions between the balls or rolling elements and the raceway grooves [9]. With proper preloading and/or interference fitting the contact loads between the rolling elements and raceway grooves far exceed those generated in the partially conforming contacts of the cage to raceway grooves or those between the rolling elements and their retaining cage pockets $[1,5,9]$. Therefore, the bearing dynamics model can be simplified to only include the effect of varying contact forces between the rolling elements and raceway grooves. The instantaneous net force resulting from these interactions together with any variations in the transmitted applied forces to the bearing supports cause the mutual convergence or separation of bearing rings. This results in 
bearing-induced vibration, which is also affected by a host of geometrical and topographical parameters. These include the presence of off-sized rolling elements [10], surface waviness of contacting solids $[5,6,11]$, faults such as pits and cracks on the contacting surfaces $[7,11]$ and dynamic variation in bearing stiffness as the result of the orbiting rolling element complement, known as the variable compliance effect [5,6,12]. This is an inherent property of a bearing, even for idealised smooth mating surfaces.

Most dynamic analyses are based on 2 degrees-of-freedom models in the radial lateral directions of bearings [11,12]. Others include axial vibration of bearings in shaft-bearing systems subjected to thrust forces [13], or up to 5 degrees-of-freedom when moment loading and centrifugal effects $[9,14]$ are taken into account. All these analyses assume dry contact of rolling elements to races with Hertzian contact conditions, which may be regarded as reasonable under elastohydrodynamic contact conditions where the lubricant film acts like an incompressible amorphous solid, with generated pressures closely conforming to Hertzian distribution. Such conditions occur under high loads and with no emerging bearing radial clearance. However, as already noted, the determination of friction is important for predicting wear, heat generation and bearing thermal stability.

It has been shown by Dareing and Johnson [15] and Mehdigoli et al [16] that lubricant film damping is insignificant under elastohydrodynamic conditions. Therefore, friction is the main source of internal damping within a rolling element bearing. There is additional dry friction between the outer bearing ring and its retaining housing. Hence, realistic models should include the solution of lubricated rolling elements-to-races contacts within the bearing dynamic analysis. Full numerical solution of a complement of rolling elements and their raceway grooves in each step of dynamic analysis is computationally very time consuming, if not impossible. Therefore, an approach was devised by Rahnejat and Gohar [17] to use extrapolated oil film thickness formulae to provide a relationship between the lubricant film thickness and the load share of each contact in a complement of rolling element bearings. The method was for a dynamic 2-dimensional bearing model of a radial deep groove ball bearing, later extended to a 5 degrees-of-freedom model by Aini et al [18] to include the effect of axial thrust and moment loading in shaft-bearing systems. Lubricant viscous friction was implicit within the oil film thickness equation used. This approach leads to reasonable bearing vibration amplitudes, unlike the dry contact models which are only suitable for the determination of spectral contributions rather than realistic vibration amplitudes. However, the lack of a predicted film shape and contact elastohydrodynamic pressure distribution precludes the direct determination of friction, including any boundary interactions as well as the effect of generated heat in the bearing. For high applied radial loads with suitably preloaded bearings, an initial bearing dynamic analysis can indicate load variation per rolling element throughout a typical orbit (cage periodic rotation). If no emerging clearances occur, a subsequent elastohydrodynamic analysis provides all the necessary bearing tribological contact conditions as already shown with thermo-elastohydrodynamic analyses, including the effect of misalignment $[19,20]$ and with isothermal contact conditions, including combined rolling, squeezing and tilting motion of rollers [8,21]. 
This paper uses the approach highlighted in [17] with lubricated contact dynamics, using an extrapolated oil film thickness equation for finite line contacts. The load per roller contact with the inner and outer raceway grooves is thus obtained through dynamic analysis. This is used in a subsequent detailed thermo-elastohydrodynamic analysis of a typical roller in a periodic cage cycle. Most reported lubricated bearing dynamics' models assume fully flooded inlet conjunctions for roller-to-races contacts. Therefore, their results may be considered to be under idealised conditions. A new boundary condition based on a zero reverse flow at the inlet of a pair of rolling surfaces; which uses Tipei's potential flow analysis with compatibility condition [22] is established. This boundary condition has recently been validated against experimental measurements [23]. Thus, the paper includes analyses which hitherto have not been reported in literature, including realistic lubricant flow rate into the contact, as well as integrating dynamics and tribological analyses for the case of finite line contacts.

\section{Method of Analysis}

\section{Bearing Dynamics}

A roller in a rolling element complement carries an instantaneous share of the overall bearing applied load. Therefore, in accord with its orbital position and the excursion of the bearing centre from that of the supported shaft, the load share of each roller varies in a quasiharmonic manner $[9-14,17]$. This means that a quasi-static analysis which is often assumed to determine roller-to-races contact load is unrealistic. The oscillatory nature of the contact load leads to the rolling elements being subjected to squeeze film motion as well as rolling, sliding and tilting motions. Hence, even with a nominally fixed applied dominant radial bearing load, the rolling elements are subject to transient loading. Therefore, a bearing dynamic model is a pre-requisite for the determination of in situ instantaneous contact conditions. With a dominant radially applied bearing load a 2 degrees-of-freedom bearing dynamics model suffices [17]. Under this condition any misalignment of rolling elements is ignored in the current analysis.

A 2 degrees-of-freedom bearing dynamic model (figure 1) takes into account the lateral radial excursions of the supported shaft centre from the nominal geometric centre of the bearing. This creates a loaded region in the bearing, where the orbiting rolling elements are subjected to increased loading and contact deformation. Any emerging clearances (unloaded regions) can result in the deviation of roller-to-races contacts from elastohydrodynamic regime of lubrication, which can cause roller-cage collisions, roller skewing and excessive sliding in the contact region. Suitable preloading and/or intereference fitting of bearings can guard against these phenomena by yielding a widely spread loaded region. An initial dynamics model can indicate the extent of load share per rolling element and aid correct preloading to avoid deviation from elastohydrodynamic conditions. 


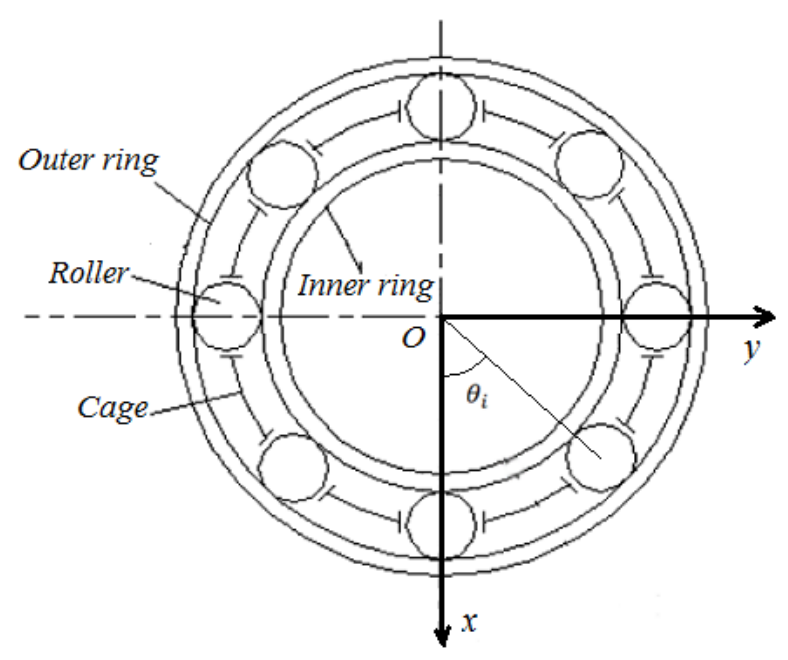

Figure 1: 2 DOF bearing dynamic model

The equations of motion for the 2 degrees-of-freedom bearing model (figure 1) are:

$$
\begin{aligned}
M \ddot{x} & =\left[\sum_{i=1}^{m}-W_{i} \cos \theta_{i}\right]-M g+F_{x} \\
M \ddot{y} & =\left[\sum_{i=1}^{m}-W_{i} \sin \theta_{i}\right]+F_{y}
\end{aligned}
$$

where, $\theta_{i}=2 \pi f_{c} t+i \frac{2 \pi}{m}, i=1 \rightarrow m$.

These equations ignore the mass of rolling elements, as in most analyses $[1,8,11,13,17,18]$. Otherwise, an m-degrees of freedom model would be required with discretisation of the supported shaft mass proportionately to these radial degrees of freedom.

In the equations of motion, $F_{x}$ and $F_{y}$ are the external excitation forces and $\theta_{i}$ is the instantaneous circumferential angular position of a rolling element $i$, whilst $W_{i}$ is its instantaneous contact load. This contact load can be obtained from the Hertzian loaddeflection relationship which is a reasonable assumption under the elastohydrodynamic regime of lubrication described in the Introduction:

$W_{i}=k_{n} \delta_{i}^{n}$

where, $k_{n}$ is the Hertzian contact stiffness non-linearity between a rolling element and the inner and outer raceway grooves. The exponent of localised deflection, $n$, is equal to $10 / 9$ for the case of rolling element bearings [1]. The deflection of a rolling element to raceway contacts, $\delta_{i}$, is as the result of the local mutual convergence of bearing rings and any initial radial clearance or interference fit there, as well as the lubricant film thickness formed [17], thus:

$2 \delta_{i}=2\left(h_{i}-C\right)+x \cos \theta_{i}+y \sin \theta_{i}$

where, $C$ is the radial local clearance. In the case of an interference fit: $C=-\bar{\rho}$ 
For finite line contact of an equivalent rigid roller against a semi-infinite elastic half-space of equivalent elastic modulus $E_{r}$, the extrapolated minimum lubricant film thickness is obtained as [24]:

$h_{i}=R_{Z X}\left[13.924 W_{i}^{*-0.045} U^{* 0.647} G^{* 0.46}\left(1-0.75 e^{132 w_{i} / U}\right)\right]$

where, $U$ is the speed of entraining motion of the lubricant into the contact of a rolling element and raceway, here taken as the inner race, thus: $U=\frac{1}{2}\left(U_{r o}+U_{r a}\right)$, and the squeeze film velocity is: $w_{i}=\frac{\partial_{i}}{\partial t}$. Note that $\frac{\partial_{i}}{\partial t}<0$ indicates normally approaching surfaces, (local convergence of the bearing rings), whereas $\frac{\partial h_{i}}{\partial t}>0$ indicates the rate of separation of the contacting surfaces. Clearly, $\frac{h_{i}}{\partial t}=0$ indicates a pure rolling contact condition. For contact separation, equation (4) is used with $\frac{\partial h_{i}}{\partial t}=0$ as the lubricant does not sustain tensile stresses. The dimensionless groups $W_{i}^{*}$ (load parameter), $U^{*}$ (speed or rolling viscosity parameter) and $G^{*}$ (the material's parameter) are given as [24]:

$W_{i}^{*}=W_{i} E_{r} / R_{Z X} L, U^{*}=\eta_{0} U E_{r} / R_{Z X}, G^{*}=\alpha E_{r}$

These equations are solved with step-by-step integration, using Runga-Kutta method, yielding values of $x$ and $y$ and the other parameters, particularly $W_{i}$ for all contacts: $i=1 \rightarrow m$.

The bearing specifications, operating conditions and lubricant properties are provided in tables A1 and A2 in the Appendix.

As in [17] the initial position is assumed to be where the centre of the shaft and the bearing are coincident at $x=y=0$. This implies an equilibrium position post any bearing housing deflection, which thereafter is assumed to behave in a rigid manner. Therefore, the equations of motion (1) account for the dynamic displacements of the supported rigid shaft relative to the geometric centre of the bearing. Of course in practice the bearing housing has certain compliance which can affect the inner dynamics of the bearing through elastic deformation of the housing support, depending on the applied bearing load, a case studied by Gao et al [25] among others. Furthermore, the supported shaft can also undergo misalignment [26] or be subjected to various bending modal responses [13]. Therefore, bearing vibration occurs about the static equilibrium position and reaches a steady state limit cycle in phase plane representation, $x, \dot{x}$ (shown in figure 2) after an initial period of transience. Two cases are presented in figure 2. One corresponds to a bearing suitably preloaded, yielding a radial interference fit of $5 \mu \mathrm{m}$ and the other represents a lightly preloaded case, yielding a zero clearance. In both cases the initial cycle (in dotted lines) of the transient behaviour (when the shaft is released from the initial position $x=y=0$ ) is retained as the shaft commences rotation at a speed of $209 \mathrm{rad} / \mathrm{s}$. The bearing reaction attempts to restore the equilibrium, yielding the limit cycle orbits for both cases, shown in full line orbits. The values $x=\delta_{05}$ and $x=\delta_{00}$ represent the static equilibrium positions under steady state conditions, with the bearing vibration represented by the indicated limit cycles. The area enclosed within the limit cycle is a measure of hysteretic losses. The line integration of the limit cycle perimeter yields 
the dominant response frequency of the bearing, which is a function of its effective stiffness, itself a function of the number of rolling elements, the extent of interference fit, shaft mass and the applied load. Rahnejat and Gohar [17] termed this dominant response frequency the base natural frequency of the bearing. Clearly, the case with an interference fit of $5 \mu \mathrm{m}$ has a shorter period of oscillation (limit cycle perimeter) and thus a higher base natural frequency than that with a zero clearance. The dominant base natural frequency of the limit cycle vibrations can best be observed in its frequency spectrum, shown in figures 3(a) and 3(b) for the interference fitted and zero clearance bearings respectively.

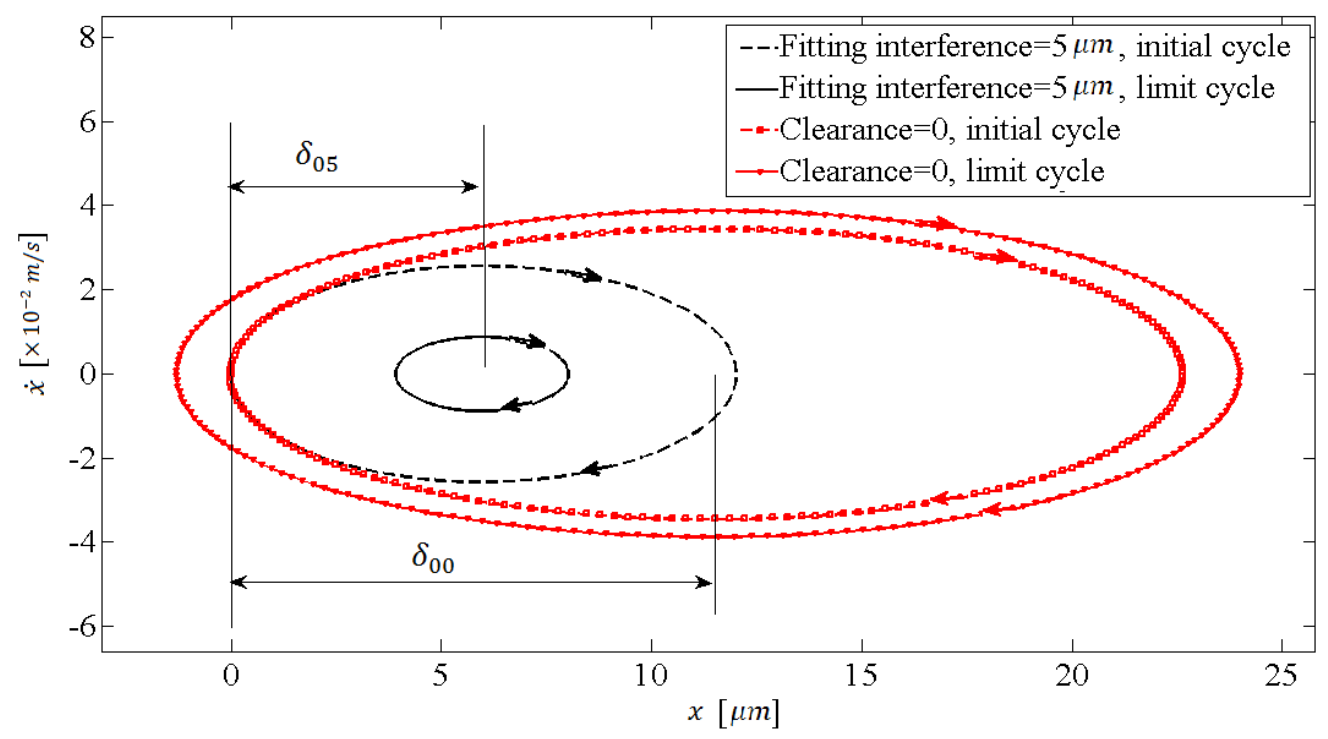

Figure 2: Phase plane representation of the bearing lateral loaded direction

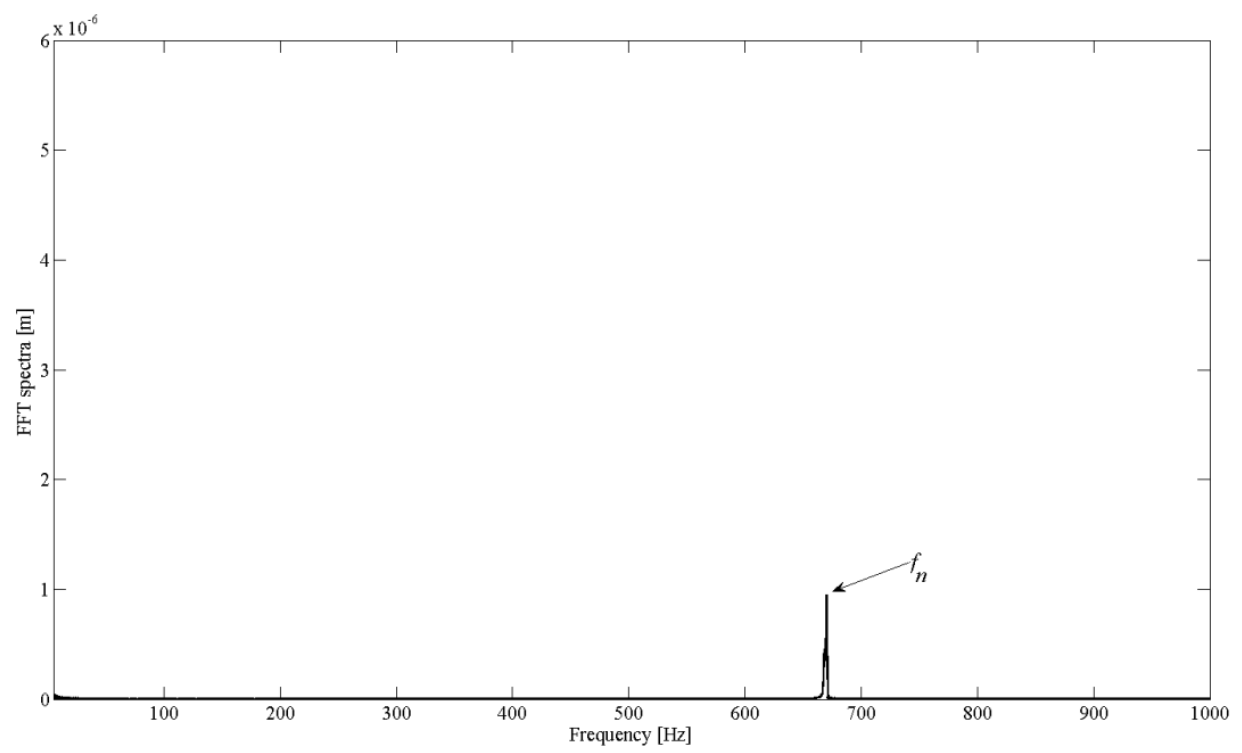

(a)- For bearing fit of $\bar{\rho}=5 \mu m$ 


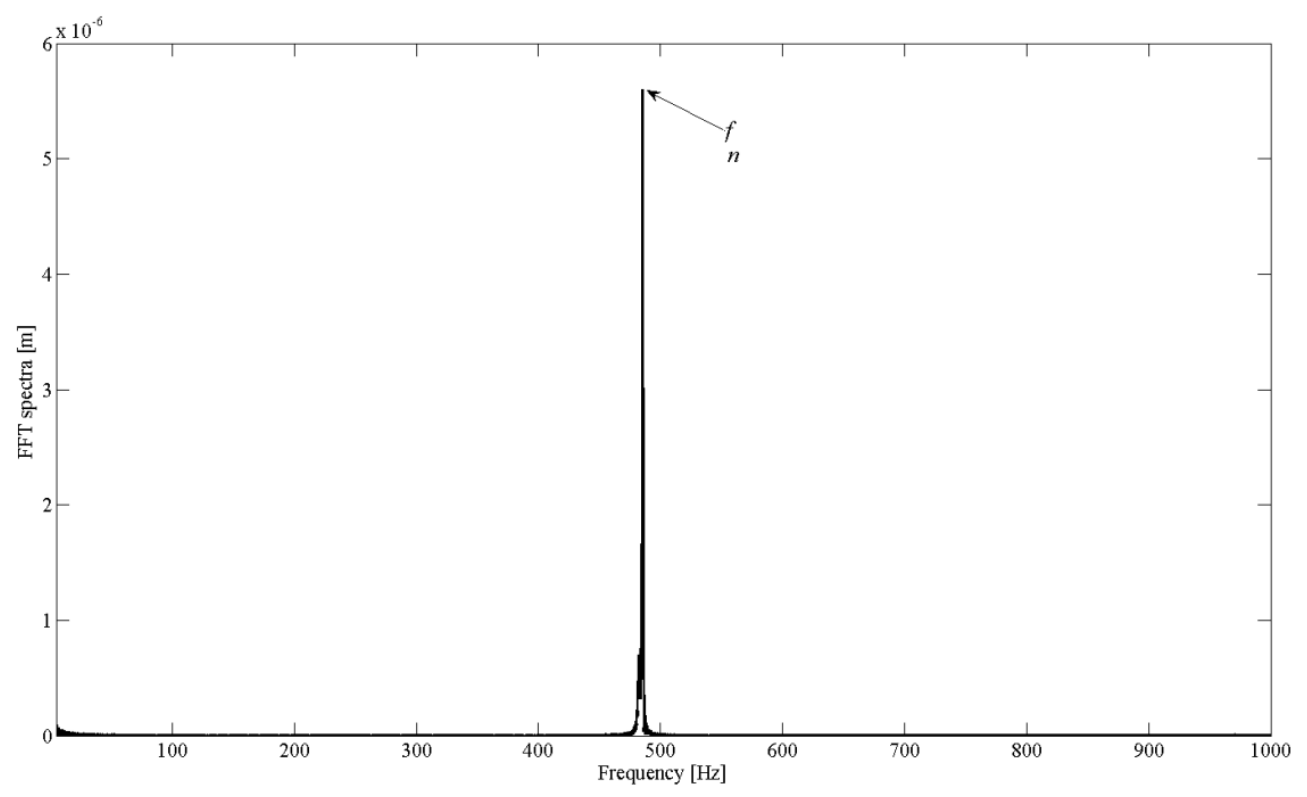

(b)- For bearing with zero clearance, $\bar{\rho}=0$

Figure 3: Spectrum of $x$-oscillations limit cycle

The spectra in figure 3 are the direct result of the effective dynamic stiffness of the bearing, affected by the contact deformation of the rolling element complement in their orbital motion about the centre of the bearing. The extent of contact stiffness variation of roller complementto-races contact is best observed by load share of a typical rolling element during a steady state cage cycle. This is shown in figure 4 for the case of $5 \mu \mathrm{m}$ interference fit. It is clear that a typical roller-to-raceways' contact is subjected to increased loading beyond the initial preload in the loaded region of the bearing in the region bounded by the section lines YY to $\mathrm{XX}$ in the figure (such as roller positions A1, B1 and C1). Conversely, reduced contact deformation occurs in the bearing arc XX to YY. Sufficient preload, as shown in the figure, ensures no loss of contact load (i.e. $W>0$ ). Clearly, a reducing preload could result in loss of contact for some of the roller complement. This occurs for the case of mutual separation of bearing rings beyond zero clearance (i.e. poorly preloaded bearings). 


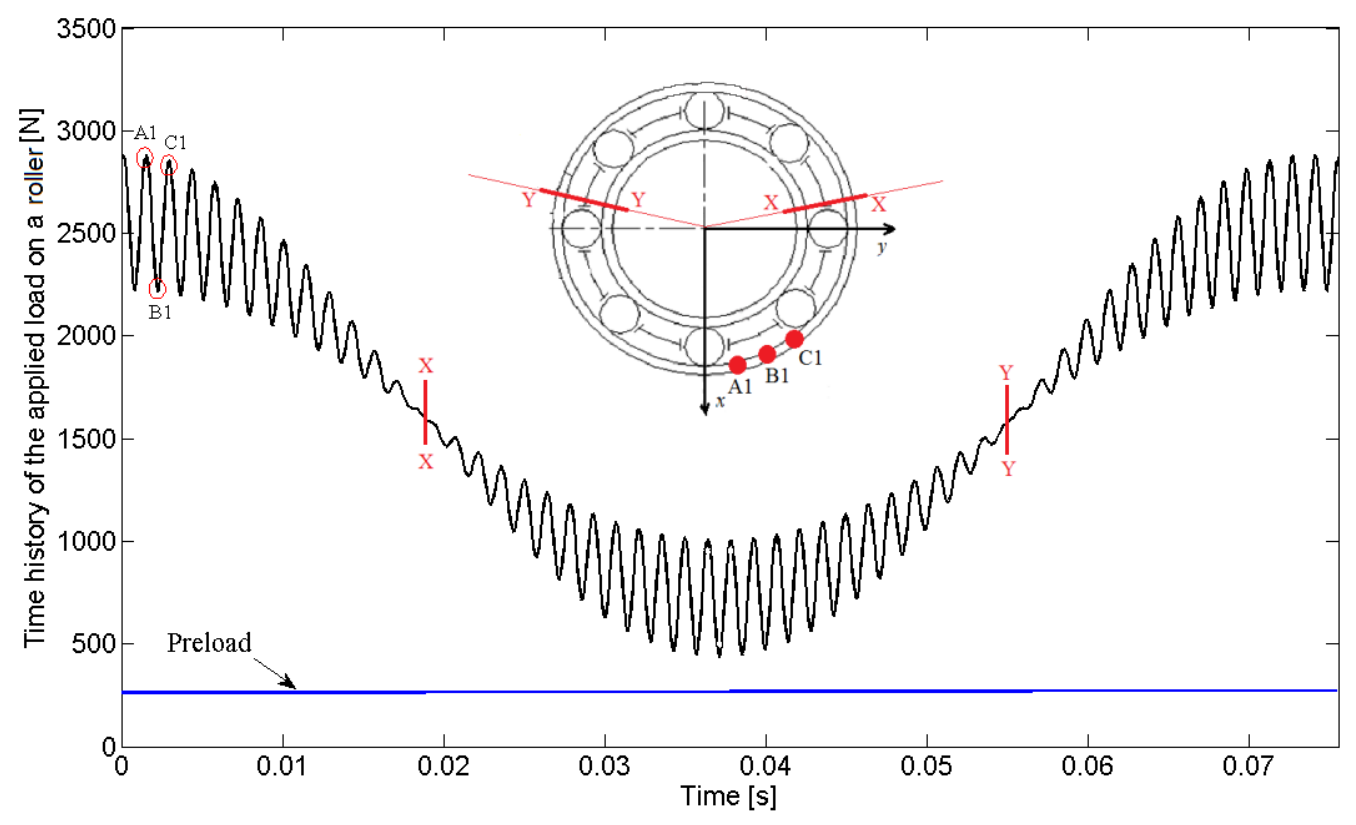

Figure 4: Load share of a typical roller-to-races’ contact during a cage cycle under steady state conditions for $\bar{\rho}=5 \mu \mathrm{m}$

The spectrum of vibration, contained in the time history of figure 4, is obtained after steady state conditions are reached for several cage cycles. This is shown in figure 5 . Two frequency contributions make the basis of the spectrum (figure 5(a)). These are the aforementioned base natural frequency of the bearing and the cage rotational frequency (the lowest bearing frequency: resulting from the cyclic repetition of the circumferential disposition of complement of rollers). Multiples of cage frequency occur because of the off-loading of roller-to-raceway contact reactions beyond the original applied preload. This is an indication of the emergence of a pronounced loaded region. In the case of the bearing with a preload of $\bar{\rho}=5 \mu \mathrm{m}$ only the second harmonic of cage frequency is noted. With zero clearance (i.e. $\bar{\rho}=0$ ) the loaded region is more pronounced, so the passage of rolling elements through it makes a more marked difference in the bearing's dynamic stiffness. As a result, higher multiples of cage speed appear in the spectrum of vibration (see figure 5(b)). In turn multiples of base natural frequency also occur as the result of variations in the effective dynamic stiffness of the bearing (in this case the super-harmonic at $2 f_{n}$ ). 


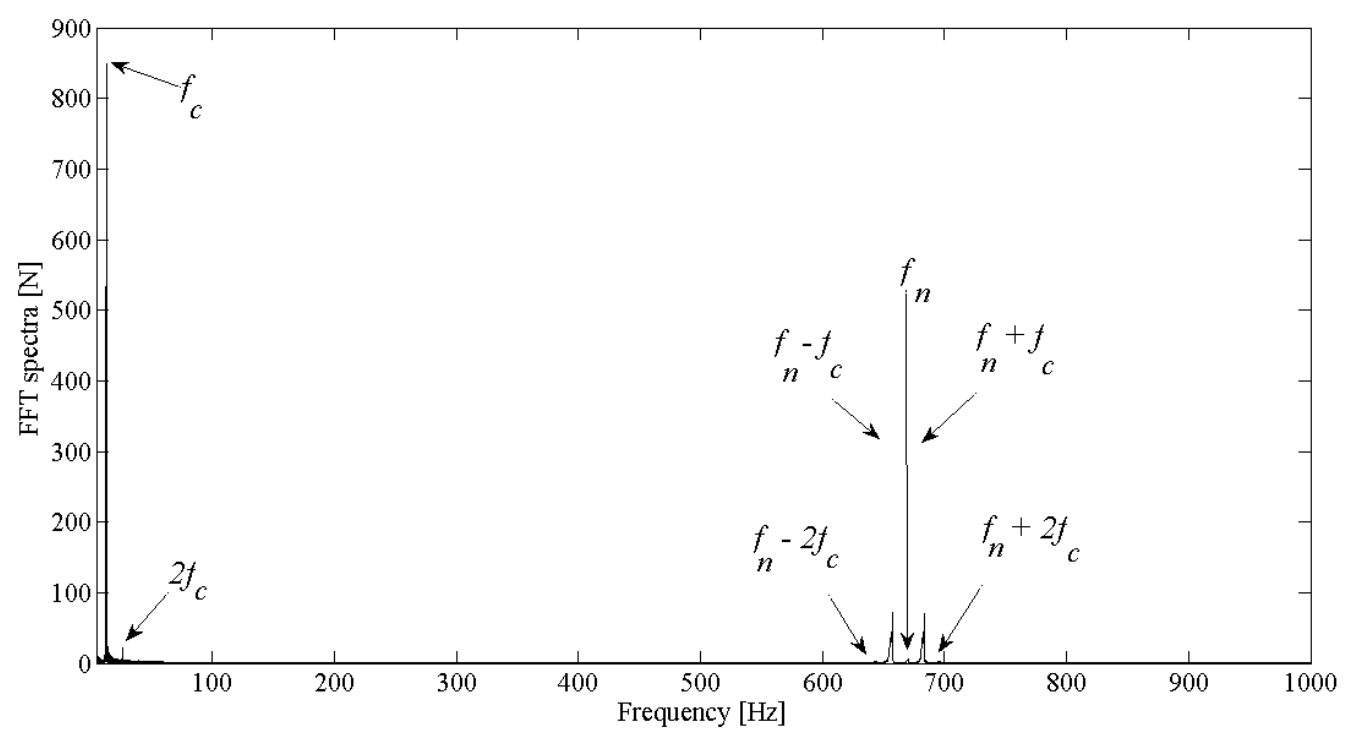

(a)- with radial interference of $\bar{\rho}=5 \mu \mathrm{m}$

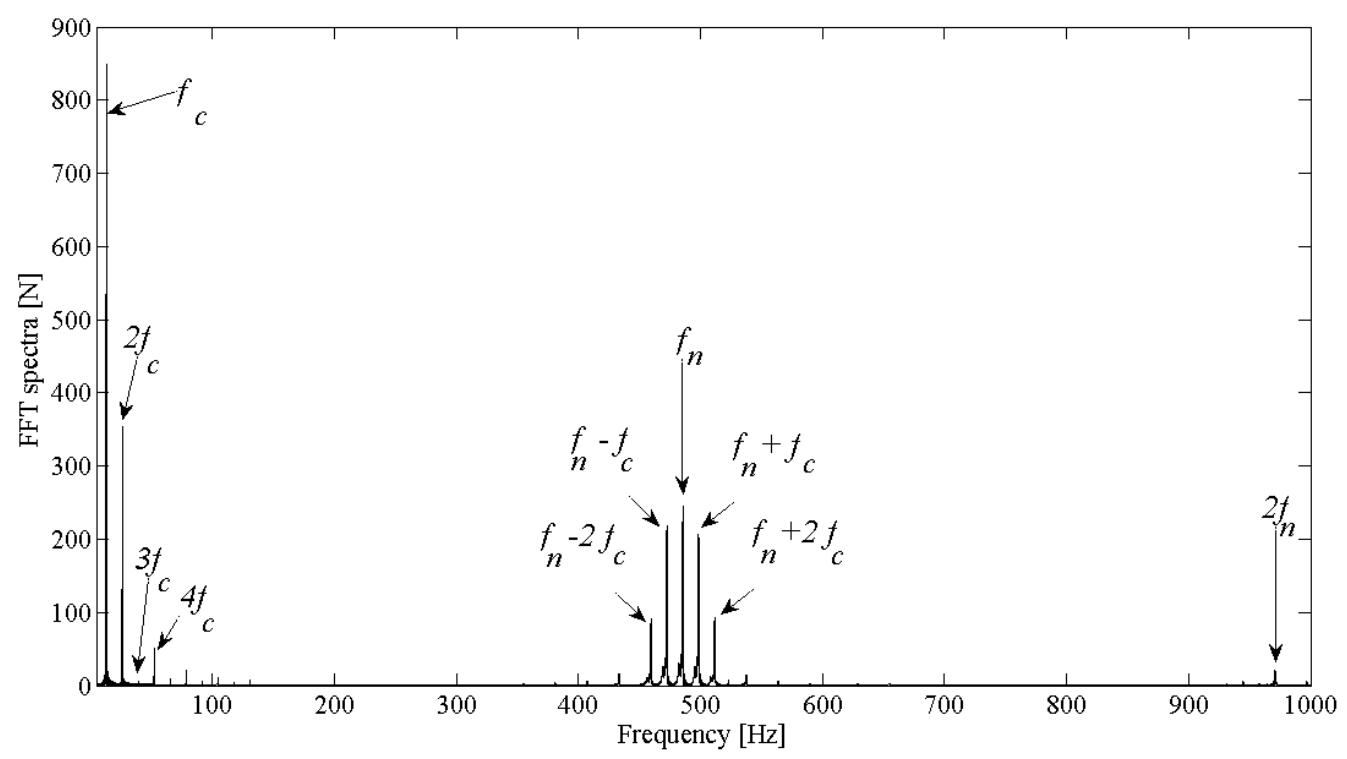

(b)- with zero radial clearance, $\bar{\rho}=0$

Figure 5: Spectra of load per rolling element contact

In the extreme case of narrow loaded regions, where the applied load dominates the bearing preload the repetitive disposition of the roller complement by the increment $\frac{2 \pi}{m}$ (i.e. roller spacing) leads to the often noted roller-passage frequency; $f_{r}=m f_{c}$. This extreme case is not noted under the simulated conditions. However, the case in figure 5(b) shows the beginning of this phenomenon for the case of a lightly preloaded zero clearance bearing, with up to 4 rollers traversing a relatively unloaded bearing region (note the contribution at $4 f_{c}$ ). 
There are also modulation effects between the base natural frequency of the bearing and the cage frequency and its multiples, with these effects becoming more significant in the case of reducing value of $\bar{\rho}$. It is also clear that resonant conditions would occur when a multiple of the cage frequency approaches the base natural frequency of the bearing.

Ref [17] provides detailed analysis of the effect of shaft mass, radial interference fit and number of rolling elements on the base natural frequency of radial deep groove ball bearings. This paper is focused on the determination of contact conditions under the prescribed dynamic analysis.

\section{Contact model:}

To determine friction and generated heat a numerical solution of the thermoelastohydrodynamic lubricated contact of roller-to-raceway is required. With the contact load variation determined in the previous section and the relative contact velocity of roller to raceway known under a given bearing operating condition, the solution can be obtained for a typical roller during the steady state repetitive cage cycle in figure 4. Reynolds equation is solved simultaneously with a contact thermal model. Reynolds equation of the following form is used to obtain the generated contact pressures:

$\frac{\partial}{\partial X}\left[\frac{\rho h^{3}}{\eta} \frac{\partial p}{\partial X}\right]+\frac{\partial}{\partial Y}\left[\frac{\rho h^{3}}{\eta} \frac{\partial p}{\partial Y}\right]=12\left\{U \frac{\partial}{\partial X}[\rho h]+\frac{\partial}{\partial t}[\rho h]\right\}$

where $X$ is the direction of entraining motion of the lubricant into the contact and $Y$ denotes the side leakage direction along the length of the roller. The side-leakage flow is considered to be negligible for the usually starved roller-to-races contacts, thus the remaining Couette flow (first term on the right-hand side of equation (5)) is that due to the lubricant entrainment in the $X$ direction only. The ultimate term on the right-hand side of equation (5) is due to squeeze film motion under oscillating conditions (this is essentially lubricant squeeze as the result of local mutual approach and separation of contacting surfaces).

The pressure distribution, $p$ is obtained, when variations in the film thickness, $h$ is known as (figure 6 shows the elastic film shape in the direction of entraining motion):

$$
h(X, Y)=h_{0}+s(X, Y)+\Delta(X, Y)
$$

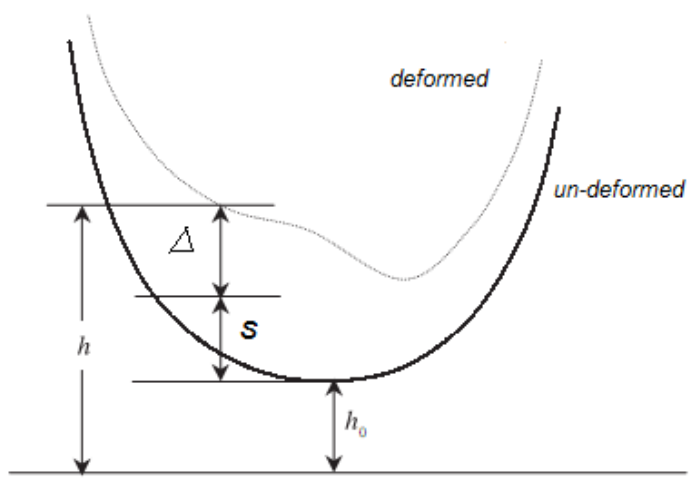

Figure 6: Film geometry 
The rolling elements used are cylindrical rollers with dub-off end profiles in the axial roller direction (Figure 7). These relief profiles are used to mitigate pressure spikes which would otherwise form at the roller extremities due to stress discontinuity [26]. The un-deformed roller conjunctional profile is thus obtained as:

$$
\begin{aligned}
& s(X, Y)=\frac{X^{2}}{2 R_{Z X}}+\frac{\left(l_{d}-Y\right)^{2}}{2 R_{d}} \quad \text { if } \quad Y \leq l_{d} \\
& s(X, Y)=\frac{X^{2}}{2 R_{Z X}} \quad \text { if } \quad l_{d}<Y<l-l_{d} \\
& s(X, Y)=\frac{X^{2}}{2 R_{Z X}}+\frac{\left(Y-\left(l-l_{d}\right)\right)^{2}}{2 R_{d}} \quad \text { if } \quad l_{d} \leq Y
\end{aligned}
$$
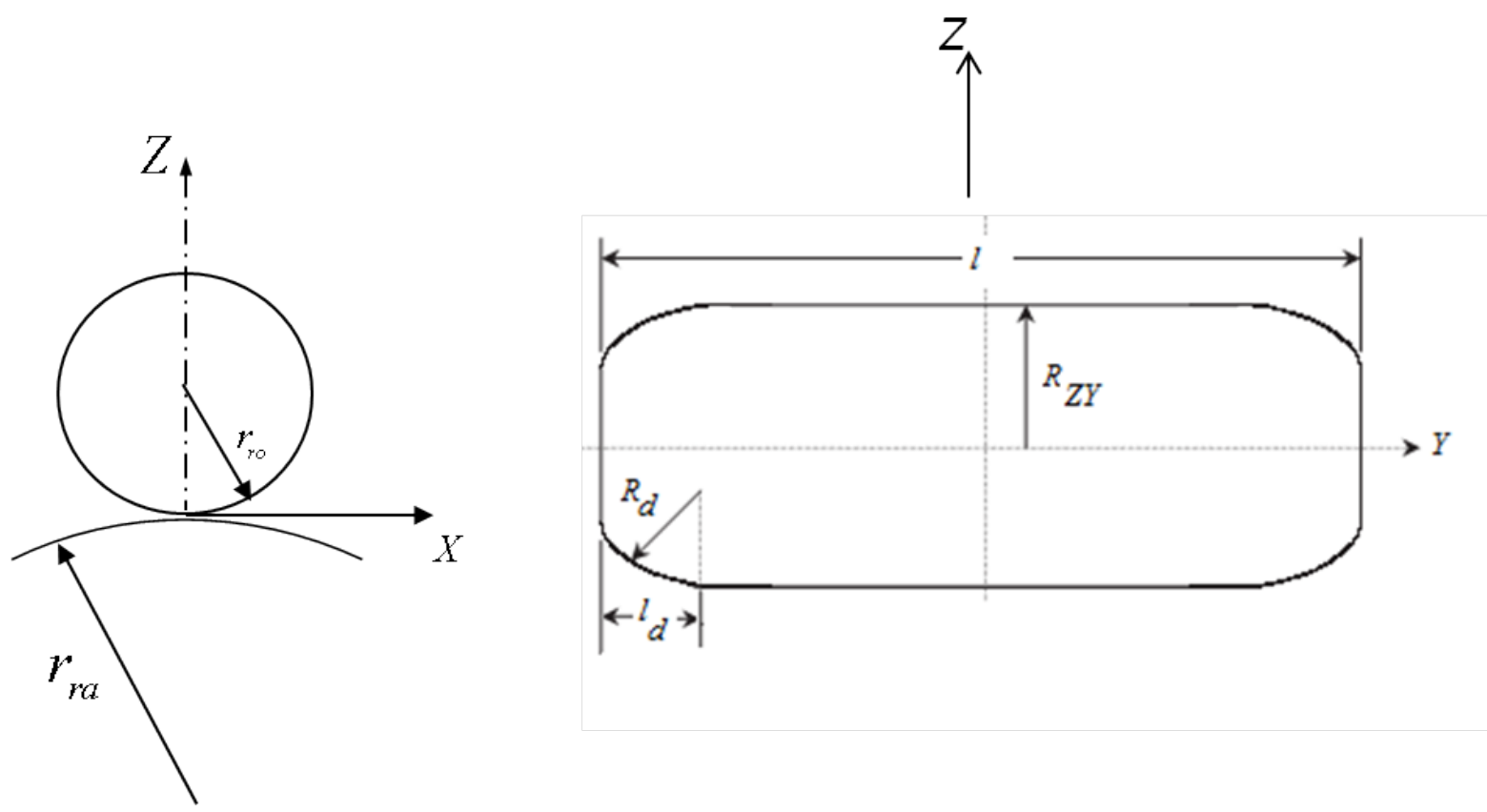

Figure 7: Roller-race contact geometry

$R_{z x}$ is the equivalent radii of contact of an ellipsoidal solid against a semi-infinite elastic halfspace, representing the instantaneous contact of any roller-to-race in the principal plane of contact $Z X$ as shown in figure 7 :

$\frac{1}{R_{Z X}}=\frac{1}{R_{r a}}+\frac{1}{R_{r o}}$

The radii of contact of the roller and the race in the $Z Y$ principal plane of contact are considered to be very large (nominally flat), thus: $R_{Z Y} \sim \infty$.

The localised contact deflection $\Delta(x, y)$ is obtained by solution of the elasticity potential integral:

$\Delta(X, Y)=\frac{1}{E_{r}} \iint_{A} \frac{p\left(X_{1}, Y_{1}\right) d X_{1} d Y_{1}}{\sqrt{\left(X-X_{1}\right)^{2}+\left(Y-Y_{1}\right)^{2}}}$ 
where $(X, Y)$ represents a point where the deflection of the semi-infinite elastic half-space of reduced elastic modulus $E_{r}$ is calculated due to any arbitrary pressure distribution $p\left(X_{1}, Y_{1}\right)$ over the contact domain; $\in\left(X_{1}, Y_{1}\right)$.

To obtain a solution to the EHL problem comprising equations (5) - (9), the lubricant rheological state is also required. The viscosity variation with pressure and temperature is given as [27]:

$\eta=\eta_{0} \exp \left\{\left(\ln \eta_{0}+9.67\right) \times\left[-1+\left(1+5.1 \times 10^{-9} p\right)^{z_{0}}\left(\frac{T-138}{T_{0}-138}\right)^{-S_{0}}\right]\right\}$

where:

$z_{0}=\frac{\propto}{5.1 \times 10^{-9}\left(\ln \eta_{0}+9.67\right)}$ and: $s_{0}=\frac{\bar{\beta}\left(T_{0}-138\right)}{\left(\ln \eta_{0}+9.67\right)}$

Lubricant density variation with pressure and temperature is given as [28]:

$\rho=\rho_{0}\left[1+\frac{0.6 \times 10^{-9} p}{1+1.7 \times 10^{-9} p}\right] \times\left[1-0.65 \times 10^{-3}\left(T-T_{0}\right)\right]$

\section{Boundary conditions:}

It is usual to assume a fully flooded inlet in the numerical analysis of elastohydrodynamic lubrication problems, where:

$X \rightarrow-\infty, p \rightarrow 0$ and $Y \rightarrow-\infty, p \rightarrow 0$

In the numerical analyses a distance of 4-5 times the Hertzian contact footprint semi-halfwidth is usually chosen in the direction of entraining motion, $X$ to represent fully flooded conditions [29].

The outlet boundary conditions usually employed are that of Swift-Stieber:

$X \rightarrow-\infty, p=\frac{\partial p}{\partial X} \rightarrow 0$ and $Y \rightarrow-\infty, p=\frac{\partial p}{\partial Y} \rightarrow 0$

However, realistic inlet and outlet distances should be used in the analysis in order to model the flooded or starved conditions (see later). Tipei [30] noted that in the inlet zone of the contact, there are swirl flows, where some reverse flow (counter flow) occurs. This was also observed experimentally by Birkhoff and Hays [31]. Physically, this means that only a fraction of the inlet lubricant flow is admitted into the contact domain, thus often causing starvation of the contact. The physical inlet is the distance to the centre of the contact footprint from the centre of the counter-flow region (the point of zero reverse flow, Figure 8). 
Tipei's method is based on the potential flows in the inlet region $\left(Q_{1}, Q_{2}, Q_{3}\right)$ in Figure 8. It should be noted that this method was developed for hydrodynamic conjunctions with relatively low pressures and negligible localised deformation, which is applicable to the inlet region of the conjunction. Applying the compatibility condition yields [30]:

$\cot ^{2} \pi\left[\frac{1}{2}-\frac{1-k}{f(k)}\right]-\cot ^{2} \pi \sqrt{\left[\frac{1}{2}-\frac{1-k}{f(k)}\right]^{2}-\frac{2 k}{f(k)}}=\cot \pi\left\{\frac{1}{2}-\frac{1-k}{f(k)}-\sqrt{\left[\frac{1}{2}-\frac{1-k}{f(k)}\right]^{2}-\frac{2 k}{f(k)}}\right\} \times$

$\cot \pi\left\{\frac{1}{2}-\frac{1-k}{f(k)}+\sqrt{\left[\frac{1}{2}-\frac{1-k}{f(k)}\right]^{2}-\frac{2 k}{f(k)}}\right\}$

where:

$k=\frac{U_{r o}}{U_{r a}}$ (is the ratio of surface speeds of the contiguous solids)

and $f(k)$ is a function of the pressure gradient in a converging gap (the inlet meniscus point A in Figure 8): $\frac{d p}{d \phi_{i}} \propto k$. Thus, for the aforementioned inlet flow rates $\left(Q_{1}, Q_{2}, Q_{3}\right)$ :

$2(1+\sqrt{k})^{2} \leq f(k) \leq 6(1+\sqrt{k})$

Values of $f(k)$ for some usually encountered cases of $k$ are listed in table 1. 


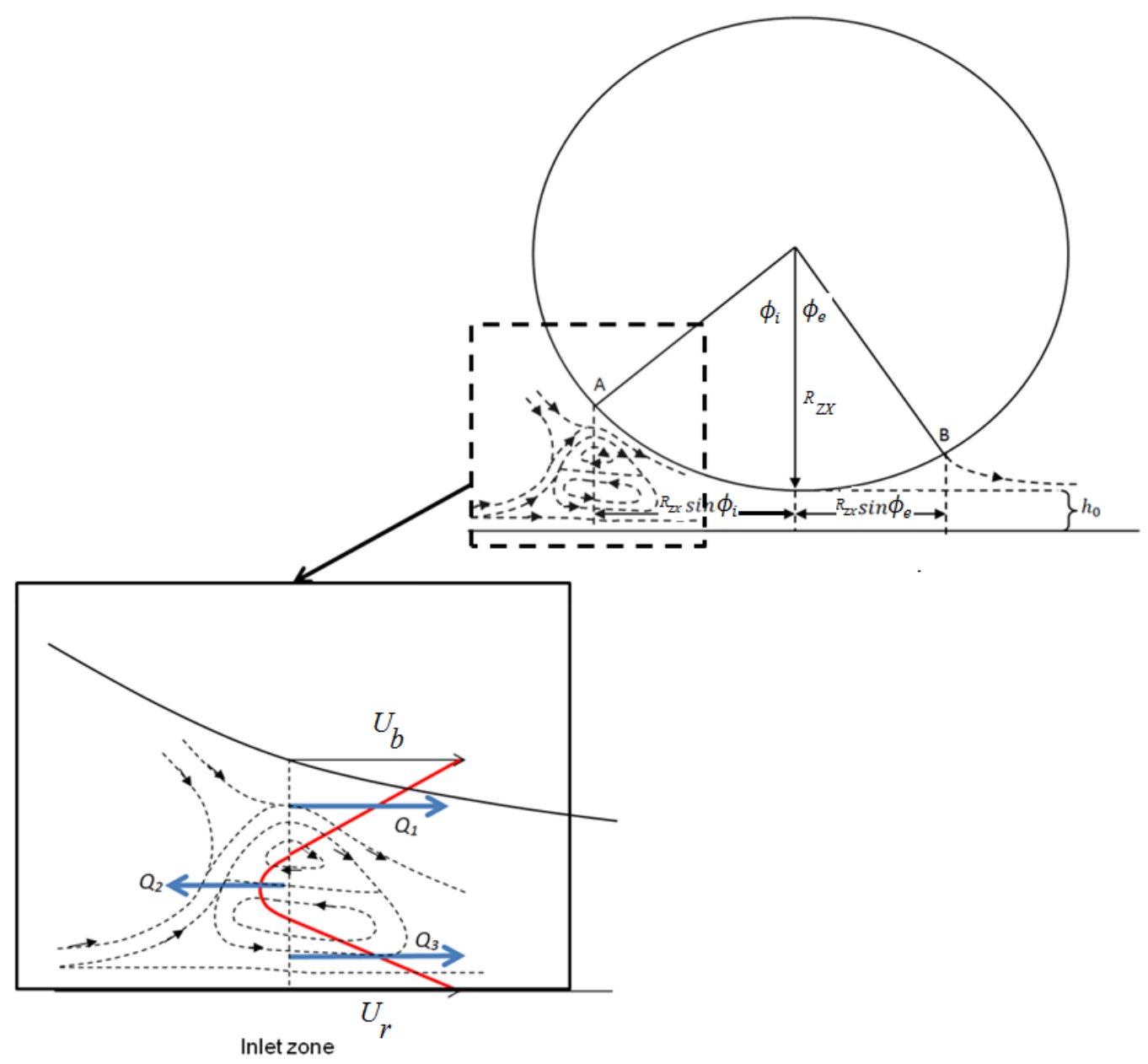

Figure 8: Flow through contact carried by the solid surfaces

Table 1: Calculated values for $f(k)$

\begin{tabular}{|c|c|}
\hline$k$ & $f(k)$ \\
\hline 0 & 4 \\
\hline 0.5 & 7.8 \\
\hline 1 & $32 / 2$ \\
\hline
\end{tabular}

Prandtl-Hopkins boundary conditions do not allow the observed swirl flow at the inlet. Thus, Tipei [30] used Swift-Stieber conditions at the inlet:

$\cos \phi_{i}=-\left[1-\frac{h_{c 0}}{R_{Z X}}\left(\cosh \vartheta_{i}-1\right)\right]$

and: 
$\cos \phi_{e}=-\left[1-\frac{h_{c 0}}{R_{Z X}}\left(\cosh \vartheta_{e}-1\right)\right]$

where:

$\frac{\cosh \vartheta_{i}}{\cosh \vartheta_{e}}=\frac{1-\frac{1}{3}\left(1+\frac{2 \sqrt{k}}{1+k}\right)}{1-\frac{f(k)}{6(1+k)}}$

Thus:

$$
\begin{aligned}
{\left[1-\frac{1}{3}\left(1+\frac{2 \sqrt{k}}{1+k}\right)\right] \tanh \vartheta_{e} } & -\left[1+\frac{f(k)}{6(1+k)}\right] \tanh \vartheta_{i} \\
- & {\left[1-\frac{f(k)}{6(1+k)}\right] \cosh \vartheta_{i}\left[\arcsin \left(\tanh \vartheta_{e}\right)-\arcsin \left(\tanh \vartheta_{i}\right)\right]=0 }
\end{aligned}
$$

The parameters $\vartheta_{e}$ and $\vartheta_{i}$ are the ratios of the film thickness at the exit and the inlet to the central lubricant film thickness respectively. The physical inlet distance $m_{i}$ and the outlet distance $m_{e}$ can now be found from the solution of equations (17)-(20) (Figure 8) as:

$$
\begin{aligned}
& m_{i}=R_{Z X} \sin \phi_{i} \\
& m_{e}=R_{Z X} \sin \phi_{e}
\end{aligned}
$$

\section{Thermal Contact model:}

There are two sources of heat generation in an elastohydrodynamic conjunction. One is due to the viscous shear of the lubricant. The other is the result of the compressive action of generated pressures. The generated heat is then carried away by the lubricant in the direction of entraining motion $X$ and any side leakage in the $Y$ direction. Some of the heat is conducted through the bounding contacting surfaces in the $Z$ direction. Thus, the energy equation can be stated as:

$\rho c\left(u_{f} \frac{\partial T}{\partial X}+v_{f} \frac{\partial T}{\partial Y}\right)=k_{f} \frac{\partial^{2} T}{\partial Z^{2}}-\frac{T}{\rho} \frac{\partial \rho}{\partial T}\left(u_{f} \frac{\partial p}{\partial X}+v_{f} \frac{\partial p}{\partial Y}\right)+\eta\left(\left(\frac{\partial u_{f}}{\partial Z}\right)^{2}+\left(\frac{\partial v_{f}}{\partial Z}\right)^{2}\right)$

Velocities and velocity gradients in the fluid film are:

$$
\begin{aligned}
& u_{f}=\frac{1}{2 \eta} \frac{\partial p}{\partial X}\left(Z^{2}-Z h\right)+\frac{z}{h}\left(U_{r o}-U_{r a}\right)+U_{r a} \\
& \frac{\partial u_{f}}{\partial Z}=\frac{1}{2 \eta} \frac{\partial p}{\partial X}(2 Z-h)+\frac{\left(U_{r o}-U_{r a}\right)}{h}
\end{aligned}
$$


$v_{f}=\frac{1}{2 \eta} \frac{\partial p}{\partial y}\left(Z^{2}-Z h\right)$

and:

$\frac{\partial v_{f}}{\partial Z}=\frac{1}{2 \eta} \frac{\partial p}{\partial Y}(2 Z-h)$

The boundary condition for the inlet lubricant temperature is assumed to be that of the housing temperature, thus:

$T\left(X_{\text {in }}, Y, Z\right)=T_{0}$

The energy equation can be transformed to that of an equivalent solid in contact with a semiinfinite plane as:

$c_{r o} \rho_{r o} U_{r o} \frac{\partial T}{\partial X}=k_{r o}\left(\frac{\partial^{2} T}{\partial X^{2}}+\frac{\partial^{2} T}{\partial Y^{2}}+\frac{\partial^{2} T}{\partial Z^{2}}\right)$

$c_{r a} \rho_{r a} U_{r a} \frac{\partial T}{\partial X}=k_{r a}\left(\frac{\partial^{2} T}{\partial X^{2}}+\frac{\partial^{2} T}{\partial Y^{2}}+\frac{\partial^{2} T}{\partial Z^{2}}\right)$

Two additional boundary conditions other than (28) are set as:

$T(X, Y,+d)=T_{0}$

$T(X, Y,-d)=T_{0}$

where, $d$ and $-d$ are the penetration depth of temperature distribution into the bounding solids. These are finite depths, sufficiently large to attain a zero temperature gradient in the Zdirection.

To satisfy the continuity of heat flux between the solid surfaces and the lubricant film, the following conditions should also be satisfied:

$k_{f} \frac{\partial T}{\partial Z}\left\{_{Z=0^{+}}=k_{\text {ro }} \frac{\partial T}{\partial Z}\left\{\begin{array}{l}Z=0^{-} \\ -\end{array}\right.\right.$

$k_{f} \frac{\partial T}{\partial Z}\left\{_{Z=h^{-}}=k_{r a} \frac{\partial T}{\partial Z}\left\{_{Z=h^{+}}\right.\right.$

\section{Determination of friction}

With an expected thin elastohydrodynamic film, a mixed regime of lubrication ensues, comprising non-Newtonian viscous shear of a lubricant film as well as interaction of ubiquitous asperities on the counterfaces (boundary friction contribution between roughness of rollers and their raceway grooves).

Greenwood and Tripp [32] model is employed for prediction of boundary friction contribution. The method assumes Gaussian distribution of asperities. A proportion of load is 
carried by the asperities on the opposing contacting surfaces, when mixed or boundary regimes of lubrication are encountered, based on the Stribeck's oil film parameter:

$\lambda=\frac{h}{\sigma} \leq 3$, where $\sigma$ is the root mean square composite surface roughness. Usually, a very small proportion of load is carried by the asperities protruding through an insufficiently thick film. The share of contact load carried by the asperities is [32]:

$W_{a}=\frac{16 \sqrt{2}}{15} \pi(\xi \beta \sigma)^{2} \sqrt{\frac{\sigma}{\beta}} E^{\prime} A F_{5 / 2}(\lambda)$

where, $E^{\prime}=\frac{2}{\pi} E_{r}$ and the statistical function $F_{5 / 2}(\lambda)$ for a Gaussian distribution of asperities can be represented by a polynomial function as [24,33]:

$F_{5 / 2}(\lambda)=\left\{\begin{array}{rr}-0.004 \lambda^{5}+0.057 \lambda^{4}-0.296 \lambda^{3}+0.784 \lambda^{2}-1.078 \lambda+0.617 & \text { for } \lambda \leq 3 \\ 0 & ; \text { for } \lambda>3\end{array}\right.$

The asperity contact area is obtained as [32]:

$A_{a}=\pi^{2}(\xi \beta \sigma)^{2} A F_{2}(\lambda)$

The statistical function $F_{2}(\lambda)$ can also be expressed through polynomial representation as [24,33]:

$F_{2}(\lambda)=\left\{\begin{array}{rr}-0.002 \lambda^{5}+0.028 \lambda^{4}-0.173 \lambda^{3}+0.526 \lambda^{2}-0.804 \lambda+0.500 ; & \text { for } \lambda \leq 3 \\ 0 \quad ; & \text { for } \lambda>3\end{array}\right.$

Usually the roughness parameter $(\xi \beta \sigma)$ is in the range $0.03-0.07$ for steel surfaces. The ratio $\sigma / \beta$ is a representation of the average asperity slope, which is in the range $10^{-4}-10^{-2}$ $[24,33]$. In the current study it is assumed that $\xi \beta \sigma=0.055$ and $\sigma / \beta=10^{-3}$.

With boundary interactions there is a thin adsorbed film at the summit of asperities or entrapped in their contact. This adsorbed film is subjected to non-Newtonian shear, thus [34]:

$f_{b}=\tau_{L} A_{a}$

where, $\tau_{L}$ is the lubricant's limiting shear stress [33, 34]:

$\tau_{L}=\tau_{0}+\chi P_{m}$

where, $P_{m}=\frac{W_{a}}{A_{a}}$, and $\chi=0.04$ for wet contact of asperity tips [34].

Viscous shear of the lubricant film is obtained as:

$\tau_{v}=\int\left[ \pm h \frac{d p}{d x}+\frac{\eta}{h}(\Delta U)\right] d A_{v}$ 
where: $A_{v}=A-A_{a} \approx A$ as $A \gg A_{a}$ which is typically less than $1 \%$ of the apparent contact area [24,32]. $\Delta U$ is the sliding velocity.

If this shear stress is below the limiting shear stress, the calculated value of shear stress from equation (7) is used. For shear values above this limiting value the limiting shear stress from equation (6) is considered. Therefore, the viscous friction force is:

$f_{v}=\iint_{A} \tau_{v} A_{v}$

Required data for calculations of boundary friction contribution is provided in table 2:

Table 2: Topographical and boundary shear data

\begin{tabular}{|c|c|c|}
\hline Parameters & Values & Units \\
\hline Composite surface roughness, $\sigma$ & 0.6 & $\mu \mathrm{m}$ \\
\hline Atmospheric limiting shear stress $\left(\tau_{0}\right)$ & 2.3 & $\mathrm{MPa}$ \\
\hline Pressure-induced shear coefficient $(\chi)$ & 0.047 & - \\
\hline
\end{tabular}

\section{Method of Solution}

The following step-wise solution is used:

Step 1: Equations (1) - (3) are solved simultaneously, using the ODE45 solver in the MatlabSimulink environment. The results provide the contact load and contact kinematics required for the mixed-thermo-elastohydrodynamic analysis.

Step 2: An initial estimation for the lubricant film thickness, $h_{0}$ is made, using equation (4).

Step 3: The inlet and outlet distances are calculated using this estimated lubricant film thickness and with the simultaneous solution of equations (17) - (20).

Step 4: Pressure distribution and film thickness are obtained through simultaneous solution of equations (5) - (13). The inlet and outlet boundaries from the previous step are used to set up the computational domain. The following convergence criterion is used:

For pressure convergence: $\sum_{A} \frac{\left|p_{\text {new }}-p_{\text {old }}\right|}{p_{\text {old }}} \leq \varepsilon_{p}$, where, typically: $10^{-4} \leq \varepsilon_{p} \leq 10^{-3}$

The method of solution used is effective influence Newton (EIN) method [32] with line distributed low relaxation iteration. When the above criterion is not satisfied, the generated pressures are under-relaxed as: $p_{\text {new }}=p_{\text {old }}+\Omega \Delta p$. The under-relaxation factor is usually $0.01 \leq \Omega \leq 0.8$

Step 5: Initially, the temperature at all the computational nodes is considered to be the inlet temperature. The temperature distribution inside the lubricant and the bounding solid contacting surfaces are obtained, using equations (23) - (33). 
At any iterative step the lubricant viscosity and density are updated for the calculated temperature and pressure distributions. The convergence criterion for the temperature distribution is:

$\sum_{V} \frac{\left|T_{\text {new }}-T_{\text {old }}\right|}{T_{\text {old }}} \leq \varepsilon_{T}$

where, $10^{-5} \leq \varepsilon_{T} \leq 10^{-4}$. If the criterion is not satisfied, then the generated temperatures are under-relaxed as: $T_{\text {new }}=T_{\text {old }}+\Omega \Delta T$. The under-relaxation factor is usually $0.005 \leq$ $\Omega \leq 0.01$.

If the above convergence criteria are not met, steps 3-5 are repeated.

Step 6: The integration of the pressure over the computational domain is calculated in order to find hydrodynamic reaction load as:

$W_{h}=\iint p d x d y$

The total instantaneous contact reaction for any roller-to-raceway contact is: $W=W_{h}+W_{a}$, where $W_{a}$ is given by equation (35). This total contact reaction, $W$ should equate the instantaneous load share of any contact $W_{i}$ obtained through dynamic analysis and equation (2). Thus, the following convergence criterion is applied:

$$
\frac{\left|W_{i}-W\right|}{W_{i}} \leq \varepsilon_{W}
$$

where, $0.001 \leq \varepsilon_{\mathrm{W}} \leq 0.05$. The value of $\varepsilon_{\mathrm{w}}=0.005$ has been used in this work. If the criterion is not met, the central film thickness $h_{\mathrm{c} 0}$ is adjusted and the entire iterative process is repeated:

$h_{c 0}^{l}=h_{c 0}^{l-1}\left(\frac{W_{i}}{W}\right)^{\varsigma}$

where, $-0.1 \leq \varsigma \leq 0.1$ is termed a damping factor.

Note that the inlet distance changes with different central film thickness and therefore the computational domain is updated accordingly.

\section{Results and discussion:}

The bearing specifications, lubricant rheology and operating conditions for the simulated cases are provided in tables A1 and A2 in the appendix. The data corresponds to the rear support roller bearing of the transmission input shaft of a heavy duty truck, equipped with a diesel engine delivering $2200 \mathrm{Nm}$ (max) torque at the nominal engine speed of $209 \mathrm{rad} / \mathrm{s}$.

Results of thermo-elastohydrodynamic conditions are provided for both the traditionally assumed fully flooded inlet condition and those with the boundary conditions developed here. 
In addition, the contact load variation in a cage cycle within the limit cycle oscillations is taken from figure 4 . The squeeze velocity is initially set to zero and obtained thereafter as: $\frac{\partial h}{\partial t}=\frac{h^{k \prime}-h^{k \prime-1}}{\Delta t}$, where the superscript $k^{\prime}$ denotes the time step of simulation and $\Delta t$ is the time-step size. Figure 9 shows the variation of squeeze velocity during a cage cycle for a typical roller-to-race contact. The variation closely follows the characteristic load per roller under bearing small amplitude oscillations.

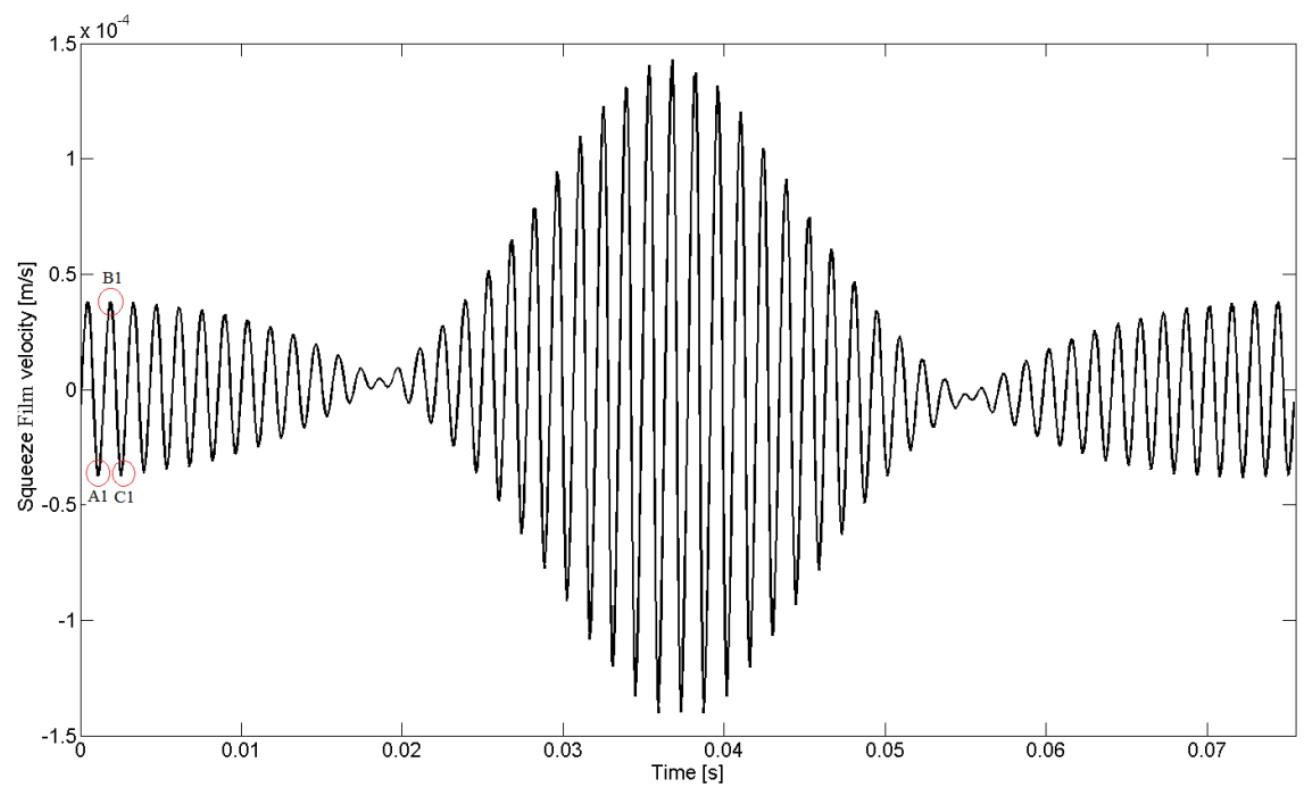

Figure 9: Squeeze film velocity

The aforementioned parameters are used to determine the lubricant film thickness and shape, as well as the corresponding pressure and temperature distributions in any roller-to-raceway contact at any instant of time. These correspond to the passage of a typical roller through various regions of the bearing, shown in figure 4. Typical results are shown in figure 10, for a roller traversing the loaded region of the bearing; positions A1, B1 and C1 in figure 4. The horizontal axis in this figure is the distance along the direction of entraining motion (along the half width of the Hertzian contact footprint). The results in figure 10 demonstrate the prevalent elastohydrodynamic regime of lubrication by the conformance of the lubricated pressure profiles to the dry elastostatic Hertzian condition (also included in the figure), except for the inlet trail and the pressure spike in the vicinity of the contact exit. These are important in the determination of film thickness, shear rate and ultimately the generated friction. Consequently, the determination of correct boundary conditions is essential for the lubricated contact analysis. A fully flooded inlet is the other extreme from a dry elastostatic Hertzian analysis, both of which may be viewed as rather idealised. Therefore, the results of the analysis with the determined new boundary conditions are also included in figure 10 . The effect of boundary conditions on the film thickness is shown in the figures.

It is important to note that a transient tribo-dynamic analysis is crucial for all the important measures of performance highlighted in the Introduction: friction, wear, thermal stability and 
fatigue. All these depend on the pressure, temperature and shear distributions, and the film thickness. The pressure distribution and the generated pressure spike determine the subsurface stress field and the fatigue performance of rolling surfaces, as shown in [2,3,24] for point contact condition and Teodorescu et al [33] for line contact of lubricated cam-tappet conjunction under transient condition. The squeeze film caving phenomenon (formation of a central dimple), resulting from local approach of bearing rings (a negative squeeze velocity) can be observed in figures $10 \mathrm{~A} 1$ and $10 \mathrm{C} 1$ (see also the corresponding points A1 and C1 in figure 9). At point B1, the mutual divergence of bearing rings occur (a positive squeeze film velocity, figure 9). There is an absence of squeeze cave in the elastic film shape. The formation of the dimple enhances the film thickness as shown in figure 10 .

The squeeze film phenomenon has been attributed to thermal wedge effect in sliding contacts by Liu et al [35]. In their case any change in the sliding velocity (Couette flow can be viewed as yielding an equivalent change in the squeeze film as [35]: $U \frac{d \rho h}{d x}=\frac{d x}{d t} \frac{d \rho h}{d x}=\frac{d \rho h}{d t}$ (see equation (5)). This is in line with squeeze cave behaviour in figure 10 and the observations in [8] that formation of the cave is because of contact kinematics (including the effect of approaching squeeze velocity) even under isothermal conditions as well as any changes in lubricant viscosity due to localised temperature conditions. Figure 10 shows the enhanced film thickness with the formation of a squeeze cave. The increased film thickness results in reduced friction because of a decrease in boundary friction contribution (for the cases A1 and C1 when compared with the case B1) as shown in table 3. The table also provides the total friction due to the prevailing mixed regime of lubrication (boundary and viscous shear of the thin non-Newtonian film). It can also be observed that with realistic boundary conditions a slightly starved contact results which marginally increases the predicted friction from its idealistic fully flooded inlet condition (by an average of 12.5\%). The instantaneous kinetic coefficient of friction can also be obtained since the contact load is known from figure 4 (marked by positions A1, B1 and C1). This is around 0.01, which is far less than the impractical dry contact Coulomb friction value of steel counterfaces of about 0.15-0.2, which is often used in dry contact analysis. 


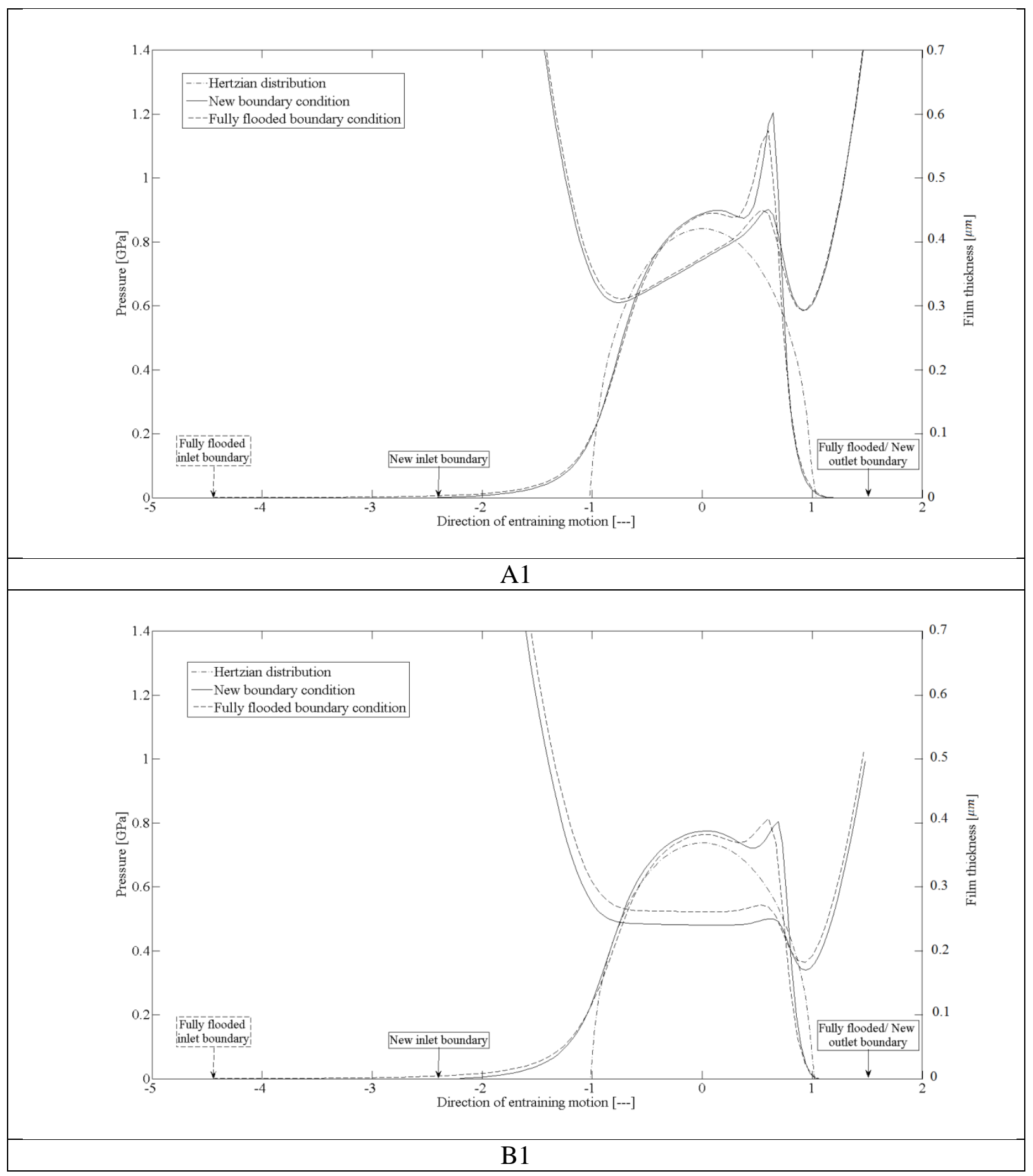




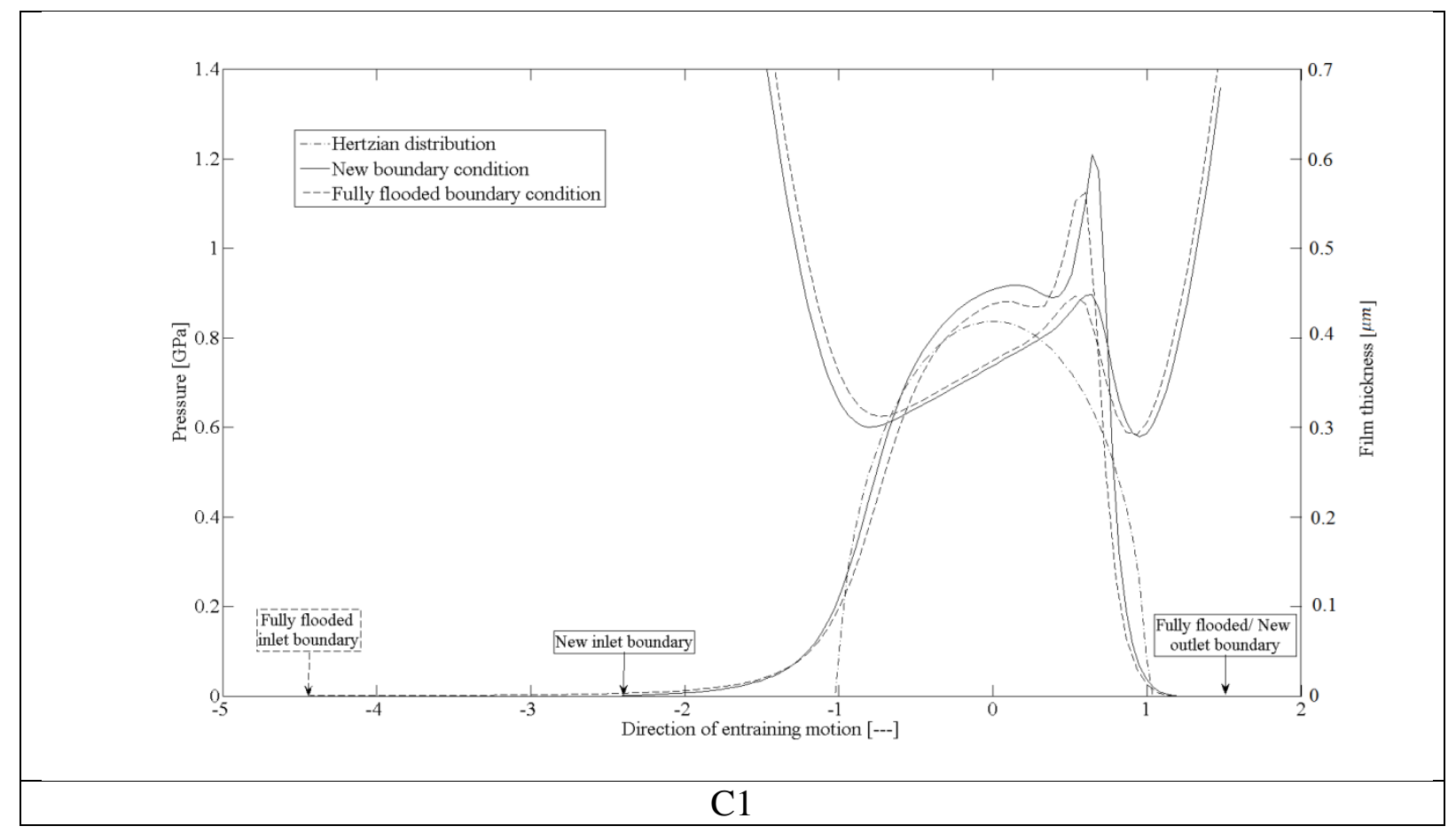

Figure 10: Film thickness and pressure distribution in the loaded region of the bearing

Table 3: Predicted friction under various conditions

\begin{tabular}{|c|c|c|c|}
\hline Orbital positions & A1 & B1 & C1 \\
\hline & & & \\
Boundary friction force [N], new boundary condition & 2.60 & 3.46 & 2.68 \\
\hline Boundary friction force [N], traditional boundary condition & 2.56 & 3.18 & 2.53 \\
\hline & & & \\
Total friction force [N], new boundary condition & 40.67 & 40.76 & 43.01 \\
\hline Total friction force [N], traditional boundary condition & 39.50 & 35.54 & 38.56 \\
\hline Power loss [Watts], new boundary condition & & & \\
\hline Power loss [Watts], traditional boundary condition & 23.95 & 24.00 & 25.32 \\
\hline
\end{tabular}

Figure 11 shows the temperature distributions through mid-plane of contact, corresponding to the results in figure 10. The temperature closely follows the same trend as the pressure distribution. An interesting point is that the reduced thermal wedge effect in figure $11 \mathrm{~B} 1$, with lack of a dimple (figure $10 \mathrm{~B} 1$ ) is a clearly an effect of contact kinematics, not the underlying cause for the squeeze caving phenomenon. Thermal analysis is, however, critical for the determination of realistic lubricant rheological state and leads to thermal thinning of the lubricant film. This has the effect of increasing contact friction through increased direct boundary interactions. 


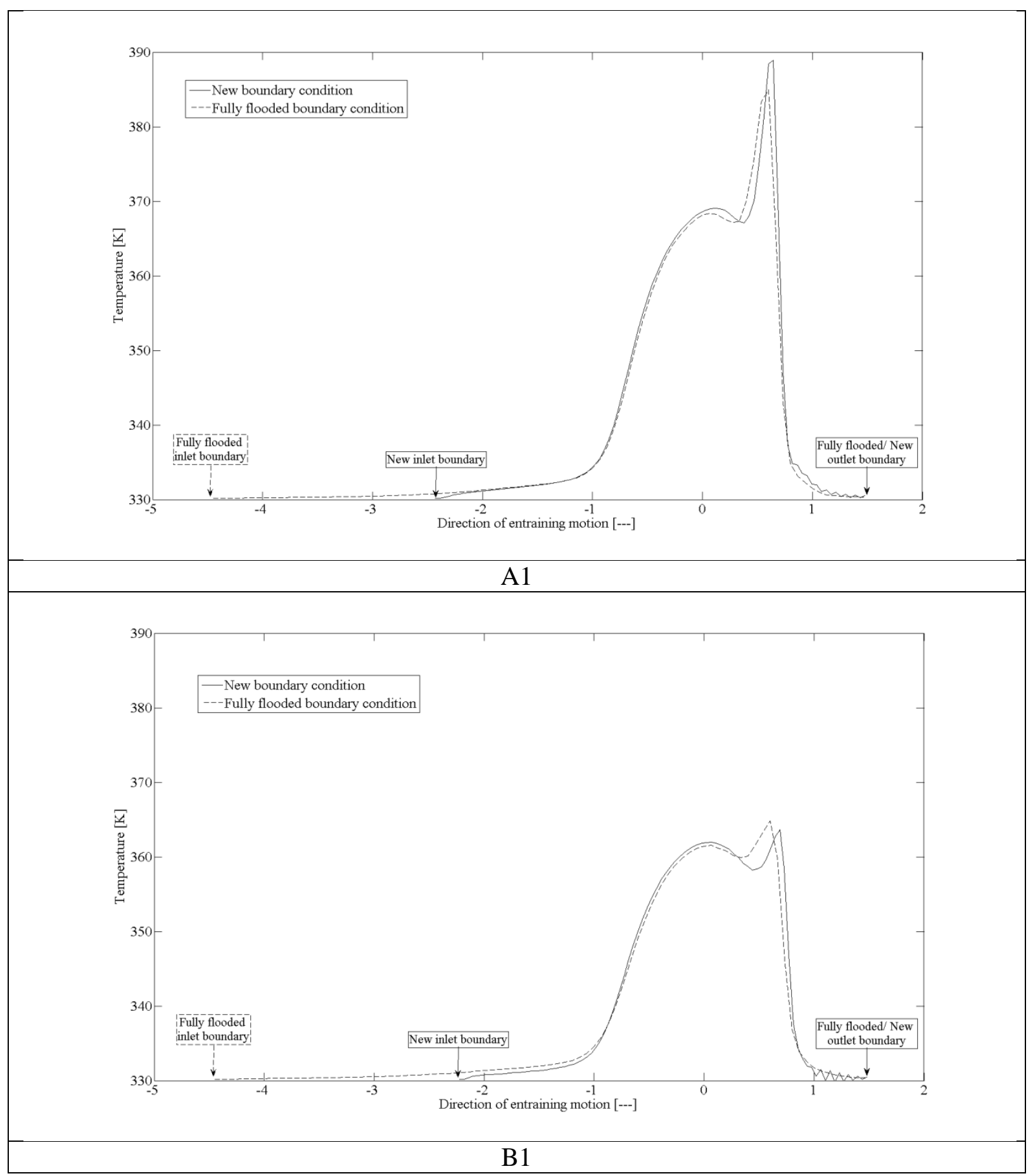




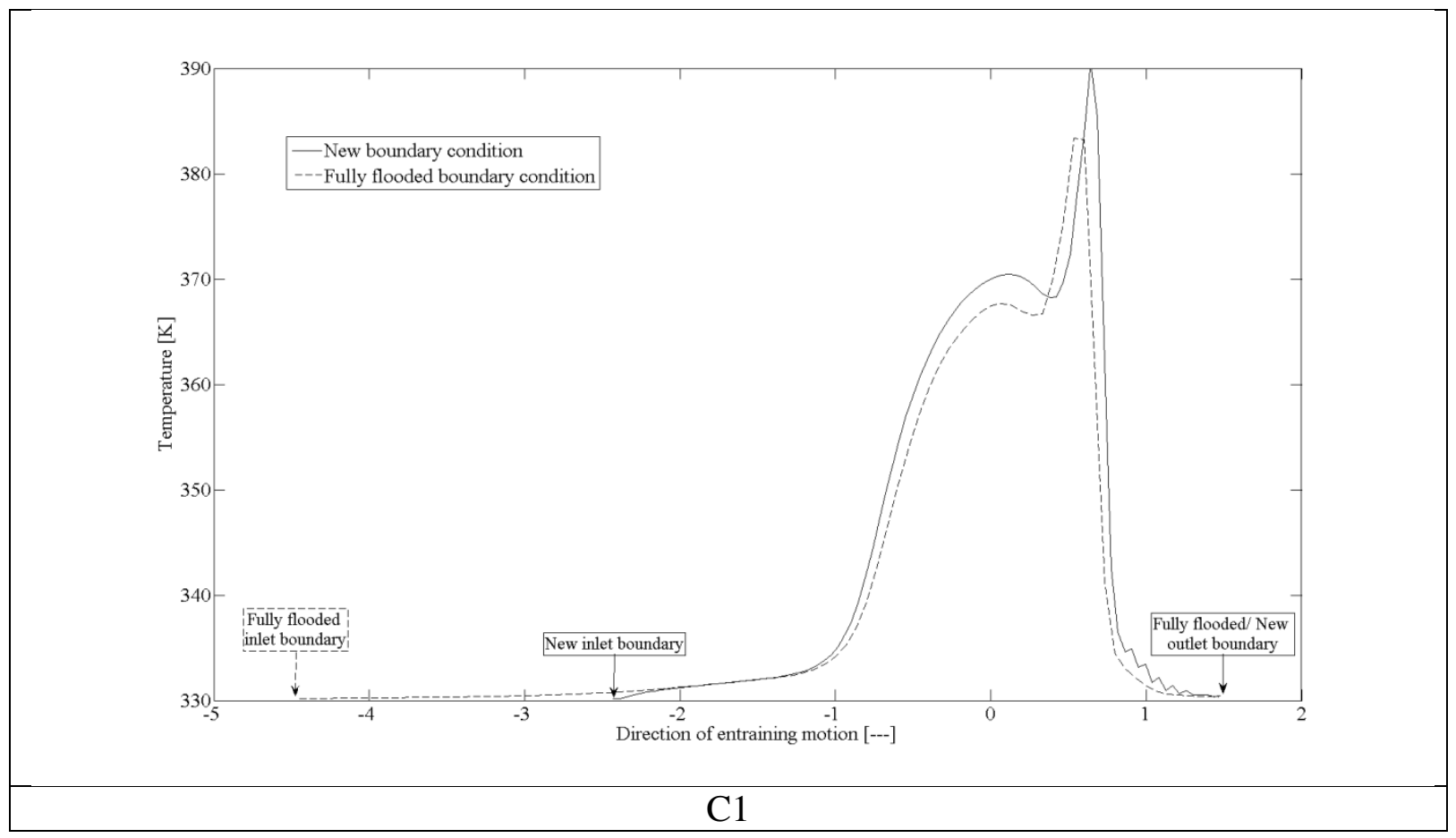

Figure 11: Temperature distribution at monitored points during one revolution

\section{Concluding remarks:}

Bearings are often the critical factors in the performance of rotating machinery. Two of the important effects are bearing dynamic performance, influencing the noise and vibration of machinery, and friction and generated heat, which affect efficiency of machinery and their structural integrity. Therefore, a holistic approach should include a tribo-dynamic analysis. It is shown that when rolling element bearings operate under elastohydrodynamic regime of lubrication the overall friction is kept to a minimum, with reduced boundary interactions. It is also clear that a combination of generated heat in the roller-to-races' contacts, high contact load and realistic boundary conditions result in partial starvation and lead to the formation of thin elastohydrodynamic films, subjected to non-Newtonian shear characteristics. Nevertheless, the effective coefficient of friction is 10 times lower than any assumed Coulomb dry contact condition. This indicates that with appropriate preloading/interference fitting roller bearings operate with reduced vibration and promote elastohydrodynamic contact conditions.

The inertial contribution of individual rolling elements in the overall shaft-bearing system is ignored in the current analysis (rolling elements are considered as massless). This is the approach used by other research workers as well, considering rolling element masses to be insignificant compared to other inertial effects. Their effect is also negligible with sufficient bearing preload and an assumed roller-to-race pure rolling contact. In practice, their inertial effect can be important with emerging clearances, rolling and sliding motion, as well as yawing and tilting with respect to their retaining cage and raceway grooves. These issues 
were considered by Gupta [14], but for dry contact conditions. The analysis presented here can be extended to cases with such complex motions with individual rolling element's inertial dynamics.

\section{Conflict of Interest:}

There is no conflict of interest to report.

\section{Acknowledgement:}

The authors wish to acknowledge the support of Wolfson School's PhD Scholarship Scheme.

\section{References:}

[1]- Harris, T.A., Rolling bearing analysis, $3^{\text {rd }}$ edition, John Wiley and Sons, New York, 1984, ISBN 0471799793.

[2]- Kannel, J. W., and Tevaarwerk., J.L., "Subsurface stress evaluations under rolling/sliding contacts" , Trans ASME, J. Tribology, 106(1), 1984, pp. 96-103.

[3]- Johns-Rahnejat, P. M., and Gohar, R., "Point contact elastohydrodynamic pressure distribution and sub-surface stress field", Tri-Annual Conf. Multi-body Dyn. Monit. Simul. Tech., Bradford, 1997.

[4]- Kim, S.M. and Lee, S.K., "Prediction of thermo-elastic behavior in a spindle-bearing system considering bearing surroundings”, Int. J. Mach. Tool \& Manuf., 41(6), 2001, pp. 809-831

[5]- Wardle, F. P., "Vibration forces produced by waviness of the rolling surfaces of thrust loaded ball bearings Part 2: experimental validation." Proc. IMechE, , Part C: J. Mech. Eng. Sci., 202 (5), 1988, pp. 313-319.

[6]- Lynagh, N. Rahnejat, H. Ebrahimi, M. and Aini, R., "Bearing induced vibration in precision high speed routing spindles”, Int. J. Mach. Tools and Manuf., 40(4), 2000, pp. 561577

[7]- Patel, U.A. and Upadhyay, S.H., “ Theoretical model to predict the effect of localized defect on dynamic behavior of cylindrical roller bearing at inner race and outer race”, Proc. IMechE, Part K: J. Multi-body Dyn., 2014, doi: 10.1177/1464419313519612

[8]- Kushwaha, M. and Rahnejat, H., "Transient concentrated finite line roller-to-race contact under combined entraining, tilting and squeeze film motions”, J. Phys., Part D: Appl. Phys., 37(14), 2004, pp. 2018

[9]- Rahnejat, $\mathrm{H}$ and Rothberg, S. "Multi-body Dynamics: Monitoring and Simulation Techniques III”, Wiley, 2004.

[10]- Vafaei, S. and Rahnejat, H., "Indicated repeatable runout with wavelet decomposition (IRR-WD) for effective determination of bearing-induced vibration”, J. Sound and Vibration, 260(1), 2003, pp. 67-82

[11]- Meyer, L. D, Ahlgren, F. F. and Weichbrodt, B., “An analytic model for ball bearing vibration to predict vibration response to distributed defects", Trans. ASME, J..Mech. Des., 102(2), 1980, pp. 205-210

[12]- Sunnersjö, C. S. "Varying compliance vibrations of rolling bearings", J. Sound and Vibration, 58(3), 1978, pp. 363-373.

[13]- Matsubara, M., Rahnejat, H. and Gohar, R., "Computational modelling of precision spindles supported by ball bearings”, Int. J. Mach. Tools and Manuf., 28(4), 1988, pp. 429442 
[14]- Gupta, P. K. "Dynamics of Rolling-Element Bearings-Part I: Cylindrical Roller Bearing Analysis" Journal of Lubrication Technology 101(3), 1979, pp. 293-302.

[15]- Dareing, D. W., and Johnson, K. L., "Fluid film damping of rolling contact vibrations", Proc. IMechE, J. Mech. Eng. Sci., 17(4), 1975, pp. 214-218.

[16]- Mehdigoli, H., Rahnejat, H. and Gohar, R., "Vibration response of wavy surfaced disc in elastohydrodynamic rolling contact”, Wear, 139((1), 1990, pp. 1-15

[17]- Rahnejat, H. and Gohar, R., “The vibrations of radial ball bearings”, Proc. IMechE, Part C: J. Mech. Eng. Sci., 199(3), 1985, pp. 181-193

[18]- Aini, R., Rahnejat, H. and Gohar, R., "A five degrees of freedom analysis of vibrations in precision spindles”, Int. J. Mach. Tools and Manufacture, 30(1), 1990, pp. 1-18

[19]- Liu, X. and Yang, P., "On the thermal elastohydrodynamic lubrication of tilting roller pairs”, Tribology Int., 65, 2013, pp. 346-353

[20]- Najjari, M. and Guilbault, R., "Edge contact effect on thermal elastohydrodynamic lubrication of finite contact lines”, Tribology Int., 71, 2014, pp. 50-61

[21]- Kushwaha, M., Rahnejat, H. and Gohar, R., "Aligned and misaligned contacts of rollers to races in elastohydrodynamic finite line conjunctions”, Proc. IMechE, Part C: J. Mech. Eng. Sci., 216(11), 2002, pp. 1051-1070

[22]- Tipei, N., "Boundary Conditions of a Viscous Flow Between Surfaces With Rolling and Sliding Motion”, Trans. ASME, J. Lubn. Tech.., 90(1), 1968, 8 pp.

[23]- Mohammadpour, M., Johns-Rahnejat, P.M., Rahnejat, H. and Gohar, R., "Boundary Conditions for Elastohydrodynamics of Circular Point Contacts”, Tribology Letts., 53(1), 2014, pp. 107-118

[24]- Gohar, R. and Rahnejat, H., "Fundamentals of Tribology", Imperial College Press, London, 2008, ISBN-10 1-84816-184-0

[25]- Gao, Y, Li, Z., Wang, J., Li, X. and An, Q., "Influences of bearing housing deflection on vibration performance of cylinder roller bearing-rotor system”, Proc. IMechE, Part K: J. Multi-body Dyn., 227(2), 2013, pp. 106-114

[26]- Johns, P.M., "The design of cylindrical rollers for use in shaft and bearing systems", Diss. MSc Thesis, Imperial College of Science and Technology, 1978

[27]- Roelands, C. J. A., "Correlation aspects of viscosity-temperature-pressure relationship of lubricating oils", PhD thesis, Delft University of Technology, Delft, The Netherlands,1966 [28]- Dowson, D., Higginson, G. R., "Elastohydrodynamic Lubrication”, 1966, Pergamon Press, Oxford

[29]- Hamrock, B.J. and Dowson, D. "Isothermal elastohydrodynamic lubrication of point contacts, Part I - Theoretical formulation”, Trans. ASME, J. Lubn. Tech., 98, 1976, pp. 223229

[30]- Tipei, N., "Boundary Conditions of a Viscous Flow Between Surfaces With Rolling and Sliding Motion”, Trans. ASME, J. Lubn. Tech., 90(1), 1968, 8 pp.

[31]- Birkhoff, G., and Hays, D., "Free Boundaries in Partial Lubrication," J. Math. and Phys., 42 (2), 1963

[32]- Greenwood, J. A. and Tripp, J. H., “The contact of two nominally flat rough surfaces”, Proc. Instn. Mech. Engrs, 185, 1970-71, pp. 625-633

[33]- Mohammadpour, M., Theodossiades, S., Rahnejat, H. and Saunders, "Non-Newtonian mixed elastohydrodynamics of differential hypoid gears at high loads", Meccanica, 49(5), 2014, pp. 1115-1138

[34]- Johnson, K. L., and R. Cameron. "Fourth Paper: Shear Behaviour of Elastohydrodynamic Oil Films at High Rolling Contact Pressures." Proc. IMechE, J. Mech. Eng. Sci., 182(1) 1967, pp. 307-330 
[35]- F Liu' F, Yang, P., Jin, Z.M. and Dowson, D., “The response of thermal Newtonian and non-Newtonian EHL to the vertical vibration of a roller", Tribology Series, Elsevier, 43, 2003, pp. 179-187

\section{Appendix:}

Table A1: Bearing specification and operating conditions

\begin{tabular}{|l|l|}
\hline Inner race bore & $40[\mathrm{~mm}]$ \\
\hline Inner race diameter & $50[\mathrm{~mm}]$ \\
\hline Outer race diameter & $75.4[\mathrm{~mm}]$ \\
\hline Roller diameter & $12.7[\mathrm{~mm}]$ \\
\hline Outer race outside diameter & $83.7[\mathrm{~mm}]$ \\
\hline Roller length & $22[\mathrm{~mm}]$ \\
\hline Dub-off radius & $50[\mathrm{~mm}]$ \\
\hline Dub-off length & $3[\mathrm{~mm}]$ \\
\hline Number of rollers & 12 \\
\hline Inner race-roller-outer race contact stiffness & $5 e 8[\mathrm{~N} / \mathrm{m}]$ \\
\hline Shaft rotational speed & $209[\mathrm{rad} / \mathrm{s}]$ \\
\hline Cage set speed & $83.26[\mathrm{rad} / \mathrm{s}]$ \\
\hline External load & $1500[\mathrm{~N}]$ \\
\hline System mass & $50[\mathrm{~kg}]$ \\
\hline Radial interference & $5[\mu \mathrm{m}]$ \\
\hline
\end{tabular}

Table A2: Lubricant and material properties

\begin{tabular}{|l|l|}
\hline Pressure viscosity coefficient $(\alpha)$ & $1.39 \mathrm{e}-8\left[\mathrm{~Pa}^{-1}\right]$ \\
\hline Temperature viscosity coefficient $(\bar{\beta})$ & $0.026\left[\mathrm{~K}^{-1}\right]$ \\
\hline Atmospheric dynamic viscosity $\left(\eta_{0}\right)$ & $0.0499[\mathrm{~Pa} . \mathrm{s}]$ \\
\hline Inlet density $\rho_{0}$ of lubricant & $829.3\left[\mathrm{~kg} / \mathrm{m}^{3}\right]$ \\
\hline Thermal conductivity of fluid & $0.14[\mathrm{~J} / \mathrm{kgK}]$ \\
\hline Heat capacity of fluid & $2000[\mathrm{~W} / \mathrm{mK}]$ \\
\hline Modulus of elasticity of contacting solids & $210[\mathrm{GPa}]$ \\
\hline Poisson's ratio of contacting solids & $0.3[-]$ \\
\hline Density of contacting solids & $7850\left[\mathrm{~kg} / \mathrm{m}^{3}\right]$ \\
\hline Thermal conductivity of contacting solids & $46[\mathrm{~W} / \mathrm{mK}]$ \\
\hline Heat capacity of contacting solids & $470[\mathrm{~J} / \mathrm{kgK}]$ \\
\hline
\end{tabular}

